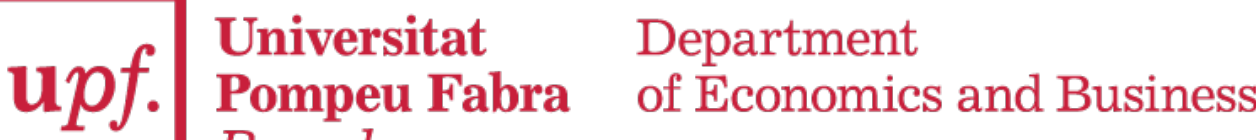 Barcelona
}

Economic Working Paper Series

Working Paper No. 1307

\section{Social capital, government expenditures and growth}

Giacomo A. M. Ponzetto and Ugo Troiano

Updated version: April 2018

(February 2012) 


\title{
Social Capital, Government Expenditures and Growth*
}

\author{
Giacomo A. M. Ponzetto \\ CREI, Universitat Pompeu Fabra, IPEG, Barcelona GSE and CEPR \\ Ugo Troiano \\ University of Michigan and NBER
}

April 2018

\begin{abstract}
This paper shows that social capital increases economic growth by raising government investment in human capital. We present a model of stochastic endogenous growth with imperfect political agency. Only some people correctly anticipate the future returns to current spending on public education. Greater social diffusion of information makes this knowledge more widespread among voters. As a result, we find it alleviates myopic political incentives to underinvest in human capital, and it helps the selection of politicians that ensure high productivity in public education. Through this mechanism, we show that social capital raises the equilibrium growth rate of output and reduces its volatility. We provide evidence consistent with the predictions of our model. Individuals with higher social capital are more informed about their government. Countries with higher social capital spend a higher share of output on public education.
\end{abstract}

Keywords: Social Capital, Education Expenditures, Economic Growth, Elections, Government Expenditures, Imperfect Information

JEL classification: D72, D83, H52, I22, I25, O43, Z13

\footnotetext{
*We are grateful for their helpful comments to Jordi Galí, Jim Hines, Joel Slemrod and seminar participants at ESSIM, the SED Annual Meetings, the CRENoS Workshop on "Institutions, Individual Behavior and Economic Outcomes," the University of Kentucky and the University of Michigan. Ponzetto acknowledges financial support from the Spanish Ministry of Science and Innovation (grant JCI-2010-08414), the Spanish Ministry of Economy and Competitiveness and its Severo Ochoa Programme for Centres of Excellence in R\&D (grants SEV-2011-0075, RYC-2013-12838, ECO-2014-59805-P and SEV-2015-0563), the Government of Catalonia and its CERCA Programme (grants 2009 SGR 1157 and 2014 SGR 830) and the BBVA Foundation through its first grant for Researchers, Innovators and Cultural Creators. Troiano acknowledges financial support from the University of Michigan, the Harvard Department of Economics, the Harvard Multidisciplinary Program in Inequality and Social Policy and the Bank of Italy. We thank Chiara Ferrero and Alex Wolfe for research assistance. The opinions expressed in this project belong to the authors and the BBVA Foundation is not responsible for them. E-mail: gponzetto@crei.cat, troiano@umich.edu.
} 


\section{Introduction}

How does social capital contribute to economic growth? A growing body of evidence documents it does (Knack and Keefer 1997; Zak and Knack 2001; Tabellini 2009; Algan and Cahuc 2010). However, the underlying causal mechanisms remain poorly understood. The very concept of social capital popularized by Putnam (1993) and Fukuyama (1995) hinders a precise study of these mechanisms because it is too broad and too vague (Solow 1995; Durlauf and Fafchamps 2005; Jackson 2010; Guiso, Sapienza and Zingales 2011). If "social capital refers to connections among individuals - social networks and the norms of reciprocity and trustworthiness that arise from them" (Putnam 2000, p. 19), surely it must have beneficial economic consequences through uncountable channels. Nonetheless, a rigorous analysis of particular transmission channels remains crucial to understanding the social determinants of economic development.

In this paper we propose and analyze one novel mechanism through which social capital causes economic growth. The greater social diffusion of information about government activity induces greater investment, as well as higher and less volatile productivity, in the provision of public education. We formalize this insight in a tractable model of stochastic endogenous growth with imperfect political agency. We then exploit survey evidence to show that the distinctive theoretical predictions of our model find empirical support at both the individual and the aggregate level. People with higher social capital are more informed about their government. Countries with higher social capital spend a higher share of income on public education.

In our model, endogenous long-run growth is supported by investments in human and physical capital. Capital accumulation cannot be undertaken by the private sector alone, but requires an indispensable government investment in public education. Politicians with heterogeneous skills set taxes and allocate spending between public education and other public services, with an eye to re-election. Voters retain or dismiss the incumbent government according to their inference of its skills, based on imperfect information. All voters observe the provision of public services that immediately raise their utility. Instead, not everyone correctly anticipates the returns to public education in terms of future economic growth. Crucially, knowledge of the effectiveness of government investment in human capital spreads through social connections.

Our precise operational definition of social capital is the rate of social diffusion of information. When it is low, we find that political career concerns induce a myopic bias in government spending. By oversupplying public services with immediate payoffs, politicians raise their appeal among all voters. By undersupplying public education, they lower their 
appeal only among a subset of more knowledgeable citizens. As a result, in equilibrium the government invests too little in human capital. When social capital is higher, however, knowledge spreads more widely across the electorate. Politicians are more likely to face electoral punishment if they mismanage public education, so they raise education spending towards the first best. Moreover, their equilibrium selection reflects more accurately their skill at managing government investment in human capital. Both better political incentives and better political selection raise the long-run growth rate of output. Better screening also reduces its short-run volatility, which stems from the endogenous evolution of stochastic government competence.

Our theory accounts for several important facts, beyond our motivating evidence that social capital raises economic growth. First, social capital is also associated with lower volatility of output growth (Sangnier 2013). Second, social capital improves both politicians' incentives and their selection (Nannicini et al. 2013; Padró i Miquel et al. 2015). Third, frictions in political agency induce underinvestment in public education, particularly in poorer countries. One reason for such insufficient investment is that voters underestimate its returns and thus have a distorted demand for education (Jensen 2010; Banerjee and Duflo 2011; Bursztyn 2016). ${ }^{1}$ Better voter information raises both the amount and the productivity of government investment in human capital (Reinikka and Svensson 2004, 2005).

In our empirical analysis, we also provide evidence in support of our two distinctive theoretical predictions that had not been brought to the data before. First, our model predicts that social capital improves government accountability by raising voter information. We test this prediction in survey data from the American National Election Studies, which include standard proxies for both social capital and political knowledge. As predicted, respondents reporting higher trust also score higher on all standard measures of information, like their ability to name candidates and incumbents or their willingness to rate politicians' ideology. We obtain analogous results if we proxy for social capital with the propensity to discuss politics with family and friends - a less standard measure, but one particularly germane to our focus on the social diffusion of information.

Turning from individual to aggregate outcomes, the key macroeconomic prediction of our model is that social capital raises the long-run growth rate by increasing the share of output devoted to public education. We test this prediction across countries, measuring social capital with averages responses in the World Values Survey. As predicted, government spending on education is a higher share of GDP in countries with higher social capital - whether

\footnotetext{
${ }^{1}$ Bursztyn (2016) shows that poverty biases people against education spending, both as voters and as parents. This bias can result both from credit constraints and from misperceptions caused by the cognitive burden of poverty (Shah, Mullainathan and Shafir 2012).
} 
measured by trust or by the likelihood of obtaining information from friends and colleagues. This relationship is robust to controlling for geographic and demographic characteristics, as well as for the overall size of government. To alleviate endogeneity concerns, we follow Tabellini's (2008) instrumental-variable strategy. Social capital is significantly predicted by the grammatical structure of a country's main language. The positive effect of social capital on public education spending is robust to the use of this instrument, which minimizes the threat of reverse causation.

Our analysis focuses on the effect of social capital on economic growth through higher public investment in education. The empirical importance of such an education channel is borne out by the findings of Gennaioli et al. (2013). Using both cross-country and crossregional data at the subnational level, they show that social capital significantly predicts economic development in a univariate setting. However, they find that this association is no longer statistically significant when controlling for human capital. The notion that higher investment in human capital is a key transmission channel for the causal effect of social capital on economic growth is also buttressed by the leading role of human capital as a driver of economic growth in general, whether across countries (Barro 1991; Manuelli and Seshandri 2014) or sub-national regions (Gennaioli et al. 2013; Islam, Minier and Ziliak 2015).

Our work is connected to several strands of literature. Most closely, a few models formalize how social capital can foster economic development by facilitating market transactions among private agents. In Zak and Knack's (2001) model, social capital alleviates agency frictions in financial intermediation, consistent with its empirical association with financial development (Guiso, Sapienza, and Zingales 2004). However, long-run growth may require a switch from transactions supported by social bonds to contracts supported by formal enforcement institutions (Routledge and von Amsberg 2003; Kumar and Matsusaka 2009; Lindner and Strulik 2015). This cautionary theoretical prediction is consistent with historical evidence (Greif 2006). We propose a complementary mechanism operating through frictions in political rather than corporate agency, and we show that social capital enables higher long-run growth by improving voters' ability to monitor their government. ${ }^{2}$ Thus, our model vindicates Bowles and Gintis's (2002) insight that social capital and government intervention may be complements rather than substitutes.

We also contribute to the broader literature in economics that provides definitions of social capital consistent with rigorous formal modeling. Our precise, tractable definition is closest to Glaeser, Laibson and Sacerdote (2002), who interpret social capital as the resources

\footnotetext{
${ }^{2}$ Empirically, social capital correlates with higher efficiency in all large organizations, whether private or public (La Porta et al. 1997).
} 
that individuals can draw upon thanks to their network of interpersonal relations - a view that harks back to sociologists' original definition of social capital (Bourdieu 1986; Coleman 1988; Lin 2001). Our focus on information is justified by the long-standing recognition that it is among the main resources obtained through social connections (Granovetter 1973; Coleman 1988; Lin 2001; Durlauf and Fafchamps 2005). Another product of social connections is trust, the standard empirical proxy for social capital (Glaeser et al. 2000; Valenzuela, Park and Kee 2009). ${ }^{3}$ The concept of social capital becomes ambiguous when it conflates social connections and shared beliefs, norms and values (Putnam 1993, 2000; Fukuyama 1995). Guiso, Sapienza and Zingales (2011) resolve this ambiguity by defining civic capital as the shared beliefs and values that help solve the problem of collective action. Both theory and empirical evidence confirm that growth-promoting cultural traits help economic development (Galor and Moav 2002; Doepke and Zilibotti 2008; Guiso, Sapienza, and Zingales 2016; Gorodnichenko and Roland 2017). Our analysis suggests that civic culture and social capital - specifically, the social diffusion of information - are distinct and complementary drivers of growth.

Our model also speaks to the political economy of public finance under imperfect information. Democratic governments underprovide public goods that are shrouded from voters' view (Eisensee and Strömberg 2007; Mani and Mukand 2007). More opaque expenditures and taxes are also more exposed to capture by special interests (Coate and Morris 1995; Ponzetto 2011; Glaeser and Ponzetto 2014). A growing body of empirical evidence shows that policy outcomes improve when citizens are more informed because politicians become more responsive to voters' needs (Besley and Burgess 2002; Reinikka and Svensson 2005; Snyder and Strömberg 2010). The literature has focused on the media as the main source of variation in voter information. We are the first to highlight theoretically and document empirically that social capital plays a similar role by acting as a knowledge multiplier.

Furthermore, we incorporate political agency and the social diffusion of information into a full-fledged model of endogenous stochastic growth. Thus, we contribute to the literature on political business cycles. Electoral pressures induce politicians to choose policies that try to deliver short-run benefits but end up imposing long-run costs (Rogoff and Sibert 1988; Persson and Tabellini 1990; Rogoff 1990). Economic performance fluctuates as politicians with heterogeneous competence win and lose elections (Alesina, Londregan, and Rosenthal 1993; Alesina and Rosenthal 1995; Alesina, Roubini, and Cohen 1997). Our analysis abstracts from variation in political incentives over the electoral calendar and from differences

\footnotetext{
${ }^{3}$ Moreover, Castelfranchi, Falcone and Marzo (2006) argue that to reap benefits from social relations it is insufficient to be merely connected, but it is necessary to be both connected and trusted. Bourlès, Bramoullé and Perez-Richet (2017) study formally the effect of altruism in social networks.
} 
in policy preferences across rival parties. On the other hand, we model for the first time social capital in this framework, and we show it can alleviate the impact of imperfect political agency on aggregate volatility.

The rest of the paper proceeds as follows. Section 2 presents our theoretical model. Section 3 presents its dynamic stochastic equilibrium and discusses how social capital and frictions in political agency determine realistic deviations from social optimality. Section 4 presents the novel empirical evidence supporting our theoretical predictions. Section 5 concludes. The Appendix provides all mathematical derivations and proofs.

\section{Theoretical Model}

\subsection{The Economic Environment}

A closed economy is populated by a measure-one continuum of infinitely lived households who have identical preferences over private consumption $c_{t}$ and government-provided public services $g_{t}$ :

$$
U_{t}=\sum_{s=0}^{\infty} \beta^{t} \mathbb{E}_{t}\left[(1-\gamma) \log c_{t+s}+\gamma \log g_{t+s}\right],
$$

where $\beta \in(0,1)$ is the discount factor and $\gamma \in(0,1)$ the relative weight of public services in the utility function. The representative household inelastically supplies one unit of labor, and its dynamic budget constraint is:

$$
a_{t+1}=R_{t} a_{t}+\left(1-\tau_{t}\right) w_{t}-c_{t}
$$

where $a_{t}$ denotes the household's assets, $R_{t}$ their gross return, $w_{t}$ labor earnings, and $\tau_{t} \in$ $(0,1)$ the tax rate on labor income. ${ }^{4}$

Firms have a Cobb-Douglas production technology and operate in perfectly competitive product and factor markets. Thus, production is represented by the neoclassical aggregate production function:

$$
y_{t}=A h_{t}^{1-\alpha} k_{t}^{\alpha} \text { for } \alpha \in(0,1)
$$

where $y_{t}$ is output, $A$ is a productivity shifter, $h_{t}$ is human capital and $k_{t}$ is physical capital. Physical capital depreciates fully every period, so its return equals: $R_{t}=\alpha y_{t} / k_{t}$. Each household is endowed with a homogeneous amount $h_{t}$ of human capital and thus earns labor earnings: $w_{t}=(1-\alpha) y_{t}$.

Physical and human capital are accumulated through investment by both private agents

\footnotetext{
${ }^{4}$ Since labor supply is perfectly inelastic, labor taxes coincide with non-distortive lump-sum taxes.
} 
and the government. The two investments are imperfect substitutes, so aggregate output has decreasing returns in each but constant returns in both together (Barro 1990). For simplicity, we assume that human capital is produced by public investment in education, while physical capital is produced by private investment. ${ }^{5}$ The physical capital stock then coincides with household assets: $a_{t}=k_{t}$ for all $t$. Since capital is not durable, the dynamic budget constraint of the private sector can be rewritten:

$$
k_{t+1}=\left[1-(1-\alpha) \tau_{t}\right] y_{t}-c_{t} .
$$

The government levies a flat tax $\tau_{t}$ on labor income and finances two types of public expenditures under a balanced-budget constraint:

$$
\tau_{t}(1-\alpha) y_{t}=x_{t}^{g}+x_{t}^{h}
$$

where $x_{t}^{g}$ denotes expenditures on public services and $x_{t}^{h}$ expenditures on public investment in education. The two expenditures translate into provision of public services and accumulation of human capital according to the stochastic technology:

$$
g_{t}=x_{t}^{g} \exp \left(\eta_{t}^{g}\right) \text { and } h_{t+1}=x_{t}^{h} \exp \left(\eta_{t}^{h}\right)
$$

Public-sector productivity $\left(\eta_{t}^{g}, \eta_{t}^{h}\right)$ represents the stochastic competence of the ruling government in providing each public good. Government competence is independent across the two types of expenditure, and it follows a first-order moving average process:

$$
\eta_{t}^{g}=\varepsilon_{t}^{g}+\varepsilon_{t-1}^{g} \text { and } \eta_{t}^{h}=\varepsilon_{t}^{h}+\varepsilon_{t-1}^{h} .
$$

The innovations $\varepsilon_{t}^{g}$ and $\varepsilon_{t}^{h}$ are independent over time, across policies, and across politicians. They are drawn from common-knowledge invariant distributions that are symmetric around their mean $\mathbb{E}_{t} \varepsilon_{t}^{g}=\mathbb{E}_{t} \varepsilon_{t}^{h}=0$. These distributions have variances $\operatorname{Var}\left(\varepsilon_{t}^{g}\right)=\sigma_{g}^{2}$ and $\operatorname{Var}\left(\varepsilon_{t}^{h}\right)=$ $\sigma_{h}^{2}$, and finite supports $\left[-\hat{\varepsilon}_{g}, \hat{\varepsilon}_{g}\right]$ and $\left[-\hat{\varepsilon}_{h}, \hat{\varepsilon}_{h}\right]$ respectively.

The dynamics of competence shocks can intuitively represent a political party that consists of overlapping generations of politicians. In each period $t$, the government comprises a cohort of senior party leaders who are approaching retirement, and a cohort of rising young politicians who will take over the party leadership in the following period. The first cohort has productivity $\left(\varepsilon_{t-1}^{g}, \varepsilon_{t-1}^{h}\right)$ and the second $\left(\varepsilon_{t}^{g}, \varepsilon_{t}^{h}\right)$, so the aggregate productivity of the

\footnotetext{
${ }^{5}$ Our results would be substantially unchanged if we assumed that future output is determined as a CobbDouglas function of four investments: private investment in physical capital, private investment in human capital, public investment in physical capital and public investment in human capital.
} 
ruling party is $\left(\eta_{t}^{g}, \eta_{t}^{h}\right)$.

The structure of our economy follows the seminal model of endogenous growth with real business cycles (King, Plosser, and Rebelo 1988). ${ }^{6}$ Our crucial innovation is that aggregate fluctuations are driven by government productivity, which is not an exogenous process as in the classic real business cycle model. The stochastic productivity of public investment in education $\left(\eta_{t}^{h}\right)$ reflects not only exogenous ability draws, but also the endogenous dynamics of electoral success. We focus on the political frictions that affect the selection of politicians and their incentives to invest in human capital. ${ }^{7}$

\subsection{Social Capital and the Political Process}

Government policy-making is the outcome of an electoral process that motivates politicians through career concerns. Politicians internalize the welfare of the representative household, out of benevolence or simply because each politician belongs to a representative household. In addition, however, a politician derives an ego rent $z>0$ in every period in which he holds office. If an incumbent is defeated in an election, his probability of returning to power in the future is nil. As a consequence, a ruling politician does not make policy decisions purely to maximize social welfare. He also aims at delivering policy outcomes that signal his ability and thereby increase his chances of re-election (Alesina and Tabellini 2008).

In the standard model of political career concerns, all voters perfectly observe all policy outcomes, though none observes the politicians' choices underpinning them. We assume that information is even less complete, and that some voters reach the election with imperfect knowledge of policy outcomes (Strömberg 2004; Boffa, Piolatto, and Ponzetto 2016). Crucially, the two types of government activity have different visibility. Public services $\left(g_{t}\right)$ generate immediate utility benefits which are directly perceived by all citizens. In contrast, public investments in human capital bear their fruits $\left(h_{t+1}\right)$ only with a lag. These returns can be correctly anticipated by some voters. The remainder remain unaware of the social returns to public education until they are realized. At the time of the election they cast their ballot based on rational expectations $\left(\mathbb{E}_{t} h_{t+1}\right)$ rather than actual observation of policy outcomes $\left(h_{t+1}\right)$.

\footnotetext{
${ }^{6}$ In particular, we follow the canonical specification of a logarithmic utility function, a Cobb-Douglas production function, and non-durable capital. These assumptions are necessary for a stochastic growth model to have an exact analytical solution (Long and Plosser 1983).

${ }^{7}$ Aside from its endogeneity, stochastic investment productivity $\left(\eta_{t}^{h}\right)$ is isomorphic to a stochastic productivity of private production $\left(\ln A_{t}\right)$. Cobb-Douglas technology implies that all productivity shocks are Hicks neutral, while full depreciation implies that lagged shocks to capital accumulation are indistinguishable from current shocks to aggregate productivity. Thus, we abstain from considering stochastic shocks to privatesector productivity, which could be added without loss of tractability but would not yield any additional insight.
} 
Recent findings in the education literature support the view that the return to public investment in education is high, but more delayed and less visible than other government expenditures. This observation is particularly consistent with the finding that returns are highest for early-childhood interventions, whose fruits are the most delayed in time (Cunha and Heckman 2008; Chetty et al. 2011); and with the finding that voters pay little heed to education policies (Bursztyn 2016). Evidence from developing countries suggests that broad misperception of the returns to education is a key determinant of educational failure (Jensen 2010; Banerjee and Duflo 2011).

The role of social capital in alleviating such misperception is the focus of our analysis. We model the social diffusion of information among voters according to the classic Bass (1969) model. Each citizen can independently learn the true returns to human-capital investment from sources such as campaigning politicians and the media. This external information acquisition takes place at a constant rate $p$ over continuous time. In addition, citizens also acquire information through social interactions with other agents. Such interactions take place at a constant rate $q$ and match random pairs of citizens. If one of them is already informed, knowledge then spreads socially to the other.

As a result, the share $\theta$ of informed voters evolves over time according to the differential equation:

$$
\theta^{\prime}=(p+q \theta)(1-\theta)
$$

Integrating Equation (8), after a unit amount of time the share of informed agents rises from zero to an eventual level:

$$
\theta(p, q)=\frac{1-e^{-p-q}}{1+(q / p) e^{-p-q}}
$$

Voter knowledge is intuitively increasing in both exogenous information acquisition $(\partial \theta / \partial p>$ $0)$ and social connectedness $(\partial \theta / \partial q>0)$.

The rate of social information diffusion $q$ provides our formal measure of social capital. It captures analytically sociologists' original definition of social capital as the resources that individuals can draw upon thanks to their network of interpersonal relations (Bourdieu 1986; Coleman 1988). It also reflects the long-standing recognition that information is among the main resources obtained from social interactions (Granovetter 1973; Lin 2001; Durlauf and Fafchamps 2005). In particular, social interactions play a key role in the acquisition of political information (Cialdini 1984; Zaller 1992; Beck et al. 2002). ${ }^{8}$

\footnotetext{
${ }^{8}$ Empirical evidence is consistent with the view that social capital raises voter awareness of all government activity. In our model, all voters are perfectly informed of the quality of current public services $g_{t}$, regardless of their level of social capital. This simplifying assumption does not materially affect our results. Our key assumption is that government investment in human capital is a relatively more opaque dimension of public spending. Even if voters were imperfectly informed about all dimensions of government activity, greater
} 
Within each period $t$, events unfold according to the following timeline.

1. All agents observe the stocks of physical capital $k_{t}$ and human capital $h_{t}$, output $y_{t}$, factor rewards $R_{t}$ and $w_{t}$, as well as the government's past competence shocks $\varepsilon_{t-1}^{g}$ and $\varepsilon_{t-1}^{h}$.

2. The government sets the tax rate $\tau_{t}$, which all citizens observe.

3. Citizens choose consumption $c_{t}$ and investment in physical capital $k_{t+1}$. Simultaneously, the government chooses expenditures $x_{t}^{g}$ and $x_{t}^{h}$. No citizen can observe directly either expenditure, though all observe their sum.

4. The government's competence shocks $\varepsilon_{t}^{g}$ and $\varepsilon_{t}^{h}$ are realized, but they are not directly observable until the following period $t+1$. The provision of public services $g_{t}$ and the accumulation of human capital $h_{t+1}$ are determined as a consequence. All citizens observe the provision of public services $g_{t}$.

5. Over an amount of time normalized to unity, each citizen independently observes $h_{t+1}$ with a learning rate $p>0$. Over the same period, information-sharing encounters between random pairs of citizens take place with a meeting rate $q>0$. When an uninformed citizen has such a meeting with an informed citizen, he endogenously learns $h_{t+1}$.

6. An election is held, pitting the incumbent against a single challenger, randomly drawn from a continuum of potential office-holders whose ability is independently realized from the same distribution.

The electoral aggregation of voters' preferences and information reflects an intensive margin of political support, following the probabilistic voting approach (Lindbeck and Weibull 1987; Persson and Tabellini 2000). Each voter's preferences consist of two independent elements. First, citizens have preferences over future policy outcomes. On the basis of all information available to him, voter $i$ has rational expectations that his future utility from private consumption and public services will be $\mathbb{E}_{t}^{i}\left(U_{t+1} \mid I_{t}\right)$ if the incumbent wins re-election, or $\mathbb{E}_{t}^{i}\left(U_{t+1} \mid C_{t}\right)$ if the challenger defeats him. In addition, voters are swayed by individual responsiveness $\xi_{I, t}^{i}$ and $\xi_{C, t}^{i}$ to the candidates' non-policy characteristics, such as their personal likability or the long-standing ideology of their party. Voter $i$ casts his ballot for the incumbent if and only if $\mathbb{E}_{t}^{i}\left(U_{t+1} \mid I_{t}\right)+\xi_{I, t}^{i} \geq \mathbb{E}_{t}^{i}\left(U_{t+1} \mid C_{t}\right)+\xi_{C, t}^{i}$.

social capital would make them disproportionately more knowledgeable about the more shrouded dimension (Glaeser and Ponzetto 2014). 
Policy preferences can be summarized by the difference $\Delta_{t}^{i} \equiv \mathbb{E}_{t}^{i}\left(U_{t+1} \mid I_{t}\right)-\mathbb{E}_{t}^{i}\left(U_{t+1} \mid C_{t}\right)$. Non-policy preferences can be disaggregated into two independent components, a common and an idiosyncratic one: $\xi_{C, t}^{i}-\xi_{I, t}^{i} \equiv \Psi_{t}+\psi_{t}^{i}$. Then $i$ supports the incumbent if and only if $\Delta_{t}^{i} \geq \Psi_{t}+\psi_{t}^{i}$. The common shock $\Psi_{t}$ is a measure of the incumbent's overall popularity, and it accounts for aggregate uncertainty in the electoral outcome. The idiosyncratic shock $\psi_{t}^{i}$ accounts for imperfect predictability of each agent's voting decision. It is i.i.d. across voters and over time. Both shocks are symmetric around zero, so non-policy preferences do not induce a systematic pro- or anti-incumbent bias. Moreover, the support of the voters' preference shocks $\Psi_{t}$ and $\psi_{t}^{i}$ is sufficiently wide, and that of the politicians' competence shocks $\varepsilon_{t}^{g}$ and $\varepsilon_{t}^{h}$ sufficiently narrow, that neither the outcome of the election nor any single voter's ballot is perfectly predictable on the basis of policy outcomes $g_{t}$ and $h_{t+1}$ alone. Finally, we assume that both $\Psi_{t}$ and $\psi_{t}^{i}$ are uniformly distributed, and denote by $\phi$ the uniform density of $\Psi_{t}$.

\subsection{Solving for the Dynamic Equilibrium}

The solution of our model describes the dynamic stochastic general equilibrium of the economy in terms of a welfare function and policy rule for private households. The additional political structure of our model entails that the solution also includes a value function for the ruling politician and the policy rule according to which he sets taxes and chooses public investment in education.

These political-economy functions are shaped by career concerns, as voters infer government competence from the provision of public services and the returns to human-capital investment. Given that ability follows a first-order moving average process, the incumbent's performance during his latest term in office contains all available information about his future competence. We will disregard the possibility of politicians developing a reputation for ignoring career concerns, and restrict our analysis to Markov perfect equilibria. The requirement of Markov perfection is not restrictive for economic decisions in our environment.

According to the sequence of events outlined above, agents make choices and inferences as follows.

1. The initial state of the economy is described by the vector:

$$
s_{t} \equiv\left(k_{t}, h_{t}, \varepsilon_{t-1}^{g}, \varepsilon_{t-1}^{h}\right),
$$

which includes the capital stocks and the known inherited components of government 
competence. Output is determined according to the aggregate production function:

$$
y_{t}=y\left(k_{t}, h_{t}\right) \equiv A h_{t}^{1-\alpha} k_{t}^{\alpha}
$$

In equilibrium, the welfare of the representative household is defined by the function $V\left(s_{t}\right)$.

2. The government sets taxes according to the equilibrium rule:

$$
\tau_{t}=T\left(s_{t}\right)
$$

3. Citizens observe the tax rate $\tau_{t}$ and choose private investment in physical capital according to the equilibrium rule:

$$
k_{t+1}=K\left(s_{t}, \tau_{t}\right) .
$$

Consumption is jointly determined by the private-sector budget constraint (Equation 4). At the same time, the government chooses public investment in education according to the equilibrium rule:

$$
x_{t}^{h}=H\left(s_{t}, \tau_{t}\right) .
$$

Expenditure on public services is jointly determined by the public-sector budget constraint (Equation 5).

4. Public-good provision is realized according to its production technology (Equation 6) and the evolution of government competence (Equation 7).

5. The observation of the state $s_{t}$, taxes $\tau_{t}$ and public services $g_{t}$, jointly with rational expectations of the strategy $H\left(s_{t}, \tau_{t}\right)$, allows all voters to infer with certainty the incumbent's competence at providing public services:

$$
\varepsilon^{g}\left(s_{t}, \tau_{t}, g_{t}\right) \equiv \log g_{t}-\log \left[\tau_{t}(1-\alpha) y\left(k_{t}, h_{t}\right)-H\left(s_{t}, \tau_{t}\right)\right]-\varepsilon_{t-1}^{g} .
$$

A fraction $\theta(p, q)$ of informed voters also learn the true value $h_{t+1}$, and can likewise infer with certainty the incumbent's competence at providing public investment in education:

$$
\varepsilon^{h}\left(s_{t}, \tau_{t}, h_{t+1}\right) \equiv \log h_{t+1}-\log H\left(s_{t}, \tau_{t}\right)-\varepsilon_{t-1}^{h} .
$$

The remaining fraction $1-\theta(p, q)$ of uninformed voters do not learn $h_{t+1}$, and therefore from their point of view $\varepsilon_{t}^{h}$ remains an unknown realization from the common- 
knowledge distribution of ability.

6. The future capital stocks $k_{t+1}$ and $h_{t+1}$ are determined before the election and do not depend on its outcome. Policy preferences hinge on the comparison between the ability of the incumbent $\left(\varepsilon_{t}^{g}, \varepsilon_{t}^{h}\right)$ and that of the challenger, which we denote by $\left(\omega_{t}^{g}, \omega_{t}^{h}\right)$. The challenger has no track record in office, so the only information about his competence is that it is an independent draw from the common distribution of ability.

Informed voters have policy preferences:

$$
\begin{aligned}
\Delta_{1}\left(s_{t}, \tau_{t}, k_{t+1}, g_{t}, h_{t+1}\right) \equiv V\left(k_{t+1}, h_{t+1}, \varepsilon^{g}\left(s_{t}, \tau_{t}, g_{t}\right)\right. & \left., \varepsilon^{h}\left(s_{t}, \tau_{t}, h_{t+1}\right)\right) \\
& -\mathbb{E}_{t} V\left(k_{t+1}, h_{t+1}, \omega_{t}^{g}, \omega_{t}^{h}\right)
\end{aligned}
$$

while uninformed voters have policy preferences:

$$
\begin{aligned}
\Delta_{0}\left(s_{t}, \tau_{t}, k_{t+1}, g_{t}\right) \equiv \mathbb{E}_{t} V\left(k_{t+1}, e^{\varepsilon_{t-1}^{h}+\varepsilon_{t}^{h}} H\left(\tau_{t}, s_{t}\right), \varepsilon^{g}\left(s_{t}, \tau_{t}, g_{t}\right), \varepsilon_{t}^{h}\right) \\
-\mathbb{E}_{t} V\left(k_{t+1}, e^{\varepsilon_{t-1}^{h}+\varepsilon_{t}^{h}} H\left(\tau_{t}, s_{t}\right), \omega_{t}^{g}, \omega_{t}^{h}\right) .
\end{aligned}
$$

Given the independent realizations of the uniform idiosyncratic shocks $\psi_{t}^{i}$, the incumbent is re-elected if and only if the realization of the aggregate popularity shock $\Psi_{t}$ is such that:

$$
\Psi_{t} \leq \theta(p, q) \Delta_{1}\left(s_{t}, \tau_{t}, k_{t+1}, g_{t}, h_{t+1}\right)+[1-\theta(p, q)] \Delta_{0}\left(s_{t}, \tau_{t}, k_{t+1}, g_{t}\right)
$$

To simplify the exposition, we give here a simplified intuitive description of the dynamic equilibrium. The complete formal definition is provided in the Appendix.

Definition 1 A Markov-perfect dynamic equilibrium consists of a welfare function $V\left(s_{t}\right)$, an additional value $Z\left(s_{t}\right)$ of holding political office, a tax-setting rule $T\left(s_{t}\right)$, a public investment rule $H\left(s_{t}, \tau_{t}\right)$, and a private investment rule $K\left(s_{t}, \tau_{t}\right)$ such that:

1. The social welfare function $V$ is defined recursively, given the policy rules $T, K$ and $H$, and the equilibrium probability of the incumbent's re-election.

2. The additional value of political incumbency $Z$ is defined recursively, given the equilibrium probability of the incumbent's re-election.

3. Labor-income taxes $T$ and expenditure on public education $H$ are chosen by the government to maximize its objective function $V+Z$, which includes both social welfare and 
the private value of re-election $Z$. The government rationally anticipates the private investment choice $K$ as well as the probability of re-election.

4. Private investment $K$ is chosen by the representative household to maximize welfare $V$. The household rationally anticipates the government investment choice $H$ as well as the incumbent's probability of re-election.

The first component of the dynamic equilibrium is the social welfare function, which is defined recursively taking into account the equilibrium policy rule. It is not simply defined by a Bellman equation because citizens choose their investment in physical capital to maximize their utility - which coincides with social welfare - but politicians instead choose taxation and investment in human capital with an eye to re-election. The outcome of the election enters the welfare function because it determines whether in period $t+1$ the government has the competence of the period- $t$ incumbent $\left(\varepsilon_{t}^{g}, \varepsilon_{t}^{h}\right)$ or the challenger's $\left(\omega_{t}^{g}, \omega_{t}^{h}\right)$.

The second equilibrium component is the additional value of political incumbency that distorts politicians' choices away from social welfare maximization. Its recursive definition is simple because all the variation is coming from the probability of re-election, which responds to equilibrium policy choices and to the realization of competence shocks.

The government's policy choices take into consideration both politicians' concern for welfare and their personal desire for re-election. The government first sets a tax rate, which determines the budget constraints of both the private and the public sector. This choice incorporates rational expectations of the investments, both public and private, that it will induce. Then the government allocates public spending taking into account the tax rate $\tau_{t}$ and the ensuing public-sector budget constraint.

At the same time, households choose consumption and savings to maximize welfare. At the time of this choice, agents observe the tax rate $\tau_{t}$ that determines the privatesector budget constraint. Both the politicians and the representative household have rational expectations over each other's simultaneous investment choice and over electoral outcomes.

Economic decisions are made by private agents and by the government based on the same information. When the household budget and the government budget are allocated, everybody knows the predetermined component of government productivity $\left(\varepsilon_{t-1}^{g}, \varepsilon_{t-1}^{h}\right)$, but nobody knows the period- $t$ innovation $\left(\varepsilon_{t}^{g}, \varepsilon_{t}^{h}\right)$. As a result, the government has no private information to signal and its policy rule depends only on public information $\left(s_{t}\right)$. Yet, policy-making crucially reflects the government's incentives to manipulate voters' information by "signal-jamming." If the government raised expenditure on one public good above the expected equilibrium amount, voters who observe the respective policy outcome would be surprised and mistakenly infer an ability innovation above its true level. 


\section{Political Agency and Equilibrium Dynamics}

\subsection{The Efficient Benchmark}

We begin by characterizing the equilibrium in the absence of political-economy frictions. The solution to the welfare-maximizing social planner's problem provides a benchmark of first-best optimality to which the equilibrium dynamics of the decentralized economy can be compared.

The benevolent planner controls both private and public spending, as well as political turnover. His choices occur with the same timing as those of the decentralized economy. He chooses $c_{t}, k_{t+1}, x_{t}^{g}$ and $x_{t}^{h}$ on the basis of $s_{t}$ alone, before the competence shocks $\varepsilon_{t}^{g}$ and $\varepsilon_{t}^{h}$ are realized. After the realization of the shocks, the planner chooses political turnover to maximize social welfare.

Again, we give here an intuitive description of the social optimum, whose formal definition is provided in the Appendix.

Definition 2 The solution to the planner's problem consists of a welfare function $V^{*}\left(s_{t}\right)$, a private investment rule $K^{*}\left(s_{t}\right)$, public spending rules $G^{*}\left(s_{t}\right)$ and $H^{*}\left(s_{t}\right)$, and a re-election rule such that:

1. The social welfare function $V^{*}$ satisfies the Bellman equation for the welfare maximization problem, and the allocation of output $\left(K^{*}, G^{*}, H^{*}\right)$ is the associated optimal policy rule.

2. The incumbent politician is re-elected if and only if

$$
V\left(K^{*}\left(s_{t}\right), e^{\varepsilon_{t-1}^{h}+\varepsilon_{t}^{h}} H^{*}\left(s_{t}\right), \varepsilon_{t}^{g}, \varepsilon_{t}^{h}\right) \geq \mathbb{E}_{t} V\left(K^{*}\left(s_{t}\right), e^{\varepsilon_{t-1}^{h}+\varepsilon_{t}^{h}} H^{*}\left(s_{t}\right), \omega_{t}^{g}, \omega_{t}^{h}\right)
$$

Unlike the dynamic equilibrium of the decentralized economy characterized in Definition 1, the planner's problem is defined by a simple Bellman equation. All distortions arise from imperfections in political agency. The politician's objective does not coincide with the voters' and the benevolent planner's because he also cares for his own re-election $(z>0)$. This private concern is irrelevant for welfare maximization, both because the incumbent is a measure-zero atomistic agent, and because in any case there is a ruling politician enjoying the value of office $z$. His identity is irrelevant for a utilitarian social welfare function. ${ }^{9}$

\footnotetext{
${ }^{9}$ Moreover, our definition of the social optimum treats as mere flukes of electoral campaigning the nonpolicy factors that randomly sway voters towards or against the incumbent $\left(\Psi_{t}\right.$ and $\left.\psi_{t}^{i}\right)$. We assume that voters are influenced by transitory popularity shocks that do not truly translate into post-election welfare gains. Thus, electoral aggregation of preferences is another source of political frictions. Even fully informed
} 
The planner's problem admits a closed-form analytical solution.

Proposition 1 The solution to the planner's problem is characterized by:

1. The social welfare function:

$$
V^{*}\left(s_{t}\right)=\frac{1}{1-\beta}\left\{\begin{array}{r}
(1-\beta)(1-\gamma) \log [(1-\beta)(1-\gamma)]+\alpha \beta \log (\alpha \beta) \\
+(1-\beta) \gamma \log [(1-\beta) \gamma]+(1-\alpha) \beta \log [(1-\alpha) \beta] \\
+\log A+\alpha \log k_{t}+(1-\alpha) \log h_{t} \\
+(1-\beta) \gamma \varepsilon_{t-1}^{g}+\beta(1-\alpha) \varepsilon_{t-1}^{h}
\end{array}\right\}
$$

2. The allocation of output:

$$
\frac{K^{*}\left(s_{t}\right)}{y\left(k_{t}, h_{t}\right)}=\alpha \beta, \frac{G^{*}\left(s_{t}\right)}{y\left(k_{t}, h_{t}\right)}=(1-\beta) \gamma, \text { and } \frac{H^{*}\left(s_{t}\right)}{y\left(k_{t}, h_{t}\right)}=(1-\alpha) \beta .
$$

3. Re-election of the incumbent politician if and only if:

$$
\gamma \varepsilon_{t}^{g}+\frac{\beta}{1-\beta}(1-\alpha) \varepsilon_{t}^{h} \geq 0 .
$$

The model is solved by the educated guess of the tractable separable form:

$$
V\left(s_{t}\right)=v_{0}+v_{k} \log k_{t}+v_{h} \log h_{t}+v_{\varepsilon}^{g} \varepsilon_{t-1}^{g}+v_{\varepsilon}^{h} \varepsilon_{t-1}^{h} .
$$

The invariant optimal allocation of output is a standard feature of analytically tractable real business cycle models. With Cobb-Douglas technology and preferences, all types of consumption and investment have constant budget shares. Consumption is optimized when the ratio of expenditure on private consumption and public services equals the ratio of their shares in the household utility function $\left(c_{t} / x_{t}^{g}=\gamma /(1-\gamma)\right)$. Investment is optimized when the ratio of investments in private capital formation and public education equals the ratio of the shares of physical and human capital in the aggregate production function $\left(k_{t+1} / x_{t}^{h}=\alpha /(1-\alpha)\right)$. With full capital depreciation every period, the allocation of output

voters fail to follow the welfare planner's optimal rule for the selection of politicians, which is based on inferred competence only. Alternatively, we could assume that the voters' taste shocks reflect a meaningful component of their welfare after the election. Then the outcome of the election would be welfare-maximizing if and only if voters are fully informed $(\theta(p, q)=1)$. Our results would be qualitatively unaffected, and the only quantitative difference would be in the distribution of the government's optimal competence $\eta_{t}^{*}$. 
between consumption and investment is optimized when their ratio equals the ratio of the discounted weights of the current period and the infinite future in the social welfare function $\left(\left(c_{t}+x_{t}^{g}\right) /\left(k_{t+1}+x_{t}^{h}\right)=(1-\beta) / \beta\right)$. All in all, output is optimally allocated to constant shares $c=(1-\beta)(1-\gamma)$ for private consumption, $x^{g}=(1-\beta) \gamma$ for government expenditure on public services, $k=\alpha \beta$ for private investment in physical capital, and $x^{h}=(1-\alpha) \beta$ for public investment in education.

While stochastic productivity is exogenous in the classic real business cycle model, the political dimension of our economy makes it endogenous to government turnover. The benevolent planner can optimally replace under-performing politicians and retain successful ones. This decision is independent of the initial state of the economy $s_{t}$, and determined exclusively by the realized competence innovations $\varepsilon_{t}^{g}$ and $\varepsilon_{t}^{h}$. The weights on the two orthogonal shocks in the welfare-maximizing re-election rule are shaped by the same consideration outlined above for the allocation of output. Government productivity in the provision of public services matters for the utility flow next period, and in proportion to the share of public services in the utility function $\gamma$. Government productivity in education investments matters for capital accumulation next period, and through it for output for the infinite future starting one period ahead (with a present value $\beta /(1-\beta)$ ), in proportion to the share of human capital in the production function $(1-\alpha)$.

Intuitively, the same weights appear also in the social welfare function that solves the planner's Bellman equation. Since the production technology gives rise to an $A K$ model of endogenous growth, both exogenous productivity $A$ and the capital stock have fully persistent effects, weighted by $1 /(1-\beta)$. The relative weights of the two types of capital are naturally their shares in the production function, $\alpha$ for physical capital and $1-\alpha$ for human capital. The predetermined shock to the productivity of government expenditure on public services $\varepsilon_{t-1}^{g}$ has a purely transient impact whose weight equals the utility share of public services $\gamma$. The predetermined shock to the productivity of government investment in education $\varepsilon_{t-1}^{h}$ has a delayed but fully predictable effect on the future stock of human capital, whose impact on social welfare is fully persistent.

The final component of the value function highlights the welfare benefits of optimal political turnover. The benevolent planner anticipates the revelation of the competence innovations $\varepsilon_{t}^{g}$ and $\varepsilon_{t}^{h}$ by the end of the period. If they prove to be low, it is optimal to replace the incumbent with a fresh challenger whose ability is a random draw with mean zero on both dimensions. However, if the incumbent is endowed with persistent high ability, welfare is maximized by retaining him and thereby ensuring that the following period's predetermined productivity is above average $\left((1-\beta) \gamma \varepsilon_{t}^{g}+\beta(1-\alpha) \varepsilon_{t}^{h} \geq 0 \Leftrightarrow \chi^{*}\left(s_{t}, \varepsilon_{t}^{g}, \varepsilon_{t}^{h}\right)=1\right)$. The value of this optimal selection rule is given precisely by the partial expectation of the combined 
welfare effect of the two skills when their aggregate is positive. ${ }^{10}$

We can complete the description of the first best by characterizing the growth path of the economy under the planner's solution.

Corollary 1 The solution to the planner's problem defines a stochastic balanced growth path. The growth rate is:

$$
\log y_{t+1}-\log y_{t}=\alpha \log \alpha+(1-\alpha) \log (1-\alpha)+\log A+\log \beta+(1-\alpha) \eta_{t}^{*}
$$

where the optimal competence of the ruling politician is:

$$
\eta_{t}^{*}=\chi^{*}\left(\varepsilon_{t-1}^{g}, \varepsilon_{t-1}^{h}\right)\left(\varepsilon_{t-1}^{h}+\varepsilon_{t}^{h}\right)+\left[1-\chi^{*}\left(\varepsilon_{t-1}^{g}, \varepsilon_{t-1}^{h}\right)\right]\left(\omega_{t-1}^{h}+\omega_{t}^{h}\right),
$$

such that $\mathbb{E}_{t} \eta_{t}^{*}>0$.

For any initial level of output $y_{0}>0$, the economy reaches immediately a stochastic balanced growth path. The average growth rate naturally reflects total factor productivity $A$ and patience $\beta$, which raises the saving rate. In addition, government efficiency in providing public investment $\left(\eta_{t}^{*}\right)$ is the stochastic process driving randomness in growth. Optimal re-election implies, as we have just seen, a filtering of persistent productivity shocks that endogenously increases trend growth $\left(\mathbb{E}_{t} \eta_{t}^{*}>0\right)$.

\subsection{The Equilibrium Growth Path}

Our main focus is on how social capital shapes distortions in public investment when political agency is imperfect. The crucial friction is that voters lack awareness of the returns to government investment in education. The lower the level of social capital, the less visible these delayed payoffs are relative to the immediate benefits of public services. As a consequence of this asymmetry, the electoral process is biased against human-capital investment.

The ensuing political-economy distortions complicate the structure of the dynamic equilibrium, as presented in Definition 1. Nonetheless, the model retains a tractable analytical solution.

Proposition 2 The equilibrium effect of social capital $q$ on the amount of public investment in education and government expenditure on public services is summarized by a monotone decreasing function $\zeta(q)$ such that $(1-\alpha) \beta>\zeta(0)>\lim _{q \rightarrow \infty} \zeta(q)=0$.

The unique Markov-perfect dynamic equilibrium is characterized by:

\footnotetext{
${ }^{10}$ We denote the partial expectation by $\mathbb{E}_{t}[X \geq 0] \equiv \int_{0}^{\infty} X d F(X)$.
} 
1. The social welfare function:

$$
\begin{aligned}
& V\left(s_{t}\right)=\frac{1}{1-\beta}\left\{\begin{array}{c}
(1-\beta)(1-\gamma) \log [(1-\beta)(1-\gamma)]+\alpha \beta \log (\alpha \beta) \\
+(1-\beta) \gamma \log [(1-\beta) \gamma+\zeta]+(1-\alpha) \beta \log [(1-\alpha) \beta-\zeta] \\
+\log A+\alpha \log k_{t}+(1-\alpha) \log h_{t} \\
+(1-\beta) \gamma \varepsilon_{t-1}^{g}+\beta(1-\alpha) \varepsilon_{t-1}^{h}
\end{array}\right\} \\
& +\beta \phi\left\{\left(\gamma \sigma_{g}\right)^{2}+\theta\left[\frac{(1-\alpha) \beta}{1-\beta} \sigma_{h}\right]^{2}\right\} \text {, }
\end{aligned}
$$

which is monotone increasing in social capital $(\partial V / \partial q>0)$.

2. The additional value of political incumbency:

$$
Z\left(s_{t}\right)=\frac{2}{2-\beta} z
$$

3. The policy rule for taxation:

$$
T\left(s_{t}\right)=\frac{(1-\alpha) \beta+(1-\beta) \gamma}{1-\alpha} .
$$

4. The policy rule for public investment in human capital

$$
H\left(s_{t}, \tau_{t}\right)=\frac{(1-\alpha) \beta-\zeta}{(1-\alpha) \beta+(1-\beta) \gamma}(1-\alpha) \tau_{t} y\left(k_{t}, h_{t}\right),
$$

such that the output shares of public investment in human capital and government expenditure on public services are:

$$
\frac{x_{t}^{h}}{y_{t}}=\beta(1-\alpha)-\zeta \text { and } \frac{x_{t}^{g}}{y_{t}}=(1-\beta) \gamma+\zeta .
$$

5. The households' rule for private investment in physical capital:

$$
K\left(s_{t}, \tau_{t}\right)=\frac{\alpha \beta}{\alpha \beta+(1-\beta)(1-\gamma)}\left[1-(1-\alpha) \tau_{t}\right] y\left(k_{t}, h_{t}\right)
$$

such that the output shares of private investment in physical capital and private consumption are:

$$
\frac{k_{t+1}}{y_{t}}=\beta \alpha \text { and } \frac{c_{t}}{y_{t}}=(1-\beta)(1-\gamma) .
$$

Like the first best, the dynamic equilibrium can be characterized by guessing that the 
value function has the form given by Equation (20). The impact of political-economy distortions is reflected in the coefficients of the welfare function, but it does not alter the overall functional form.

A second educated guess concerns the value of incumbency in the political equilibrium, which is a constant independent of the state of the economy $s_{t}$. This is an intuitive property of the model of political career concerns, which follows from the symmetry of the ruling politician's and the voters' information when policy choices are made. The incumbent has no private information to signal, and he cannot fool rational voters in equilibrium. His reelection then depends exclusively on the realizations of the shocks $\varepsilon_{t}^{g}$, $\varepsilon_{t}^{h}$, and $\Psi_{t}$. Since their distribution is invariant, so is the probability of re-election and hence the value of holding office.

The exact solution for the value of incumbency $Z\left(s_{t}\right)$ highlights the absence of any incumbency bias. In equilibrium, each candidate has an equal ex-ante likelihood of winning each election. Thus, the expected net present value of office-holding is discounted both for a pure time preference $\beta$ and for a constant hazard rate $1 / 2$ of losing re-election and thus terminating the otherwise infinite stream of benefits $z$.

The differences between the equilibrium welfare function $V\left(s_{t}\right)$ from Proposition 2 and the first-best welfare function $V^{*}\left(s_{t}\right)$ from Proposition 1 reflect the two distortions that arise from the asymmetric visibility of immediate public-service provision and delayed returns to human-capital investment. Voters cannot reward public investment in education if they have failed to learn of its delayed returns. This entails both a distortion in politicians' incentives to invest in human capital or to provide public services, and a distortion in the selection of politicians based on their skill at providing either public good.

The first distortion translates into a suboptimal allocation of output, which in turn permanently shifts down welfare as shown in the second line of the exact solution for $V\left(s_{t}\right)$. In equilibrium as in the first best, the GDP shares of private consumption, private investment in physical capital, public investment in human capital, and government expenditure on public services are all constant and independent of the state of the economy. However, politicians' incentives are skewed towards the provision of the more observable public services and against the less visible public investment in education.

Intuitively, if the government deviated from equilibrium policy by lowering expenditure on education and raising expenditure on public services, its popularity among voters would increase. All voters would observe surprisingly high provision of public services $\left(g_{t}\right)$ and would accordingly be fooled into inferring greater than actual competence at providing them $\left(\varepsilon_{t}^{g}\right)$. Conversely, only a subset of voters would also observe surprisingly low provision of human-capital investment $\left(h_{t+1}\right)$ and accordingly infer lower than actual education-specific 
competence $\left(\varepsilon_{t}^{h}\right)$. In a rational expectations equilibrium, the temptation to surprise the voters is eliminated only because government education spending is permanently too low a share of output $\left(x_{t}^{h} / y_{t}<\beta(1-\alpha)\right)$. Populist expenditure on current public services is instead too high $\left(x_{t}^{g} / y_{t}>(1-\beta) \gamma\right)$.

Higher social capital alleviates this distortion by improving the social diffusion of information about education policy. As a result, more citizens learn about the returns to human-capital investment before the election. The visibility of government services and education investment becomes less asymmetric. Therefore, political incentives are less skewed towards the provision of crowd-pleasing public services. In response, public investment $x_{t}^{h}$ rises while spending on immediate public consumption $x_{t}^{g}$ falls $(\partial \zeta / \partial q<0)$. The political equilibrium moves closer to the optimum. However, it can never reach the optimum for any finite level of social capital. Only in the limit does the social diffusion of information become perfect, so all citizens learn in advance about the returns to public investment, the government's policy choices become undistorted by political career concerns and the allocation of output becomes optimal $\left(\lim _{q \rightarrow \infty} \zeta(q)=0\right)$.

Our model thus accounts for the empirical evidence that social capital was a key driver of the rapid rise of the public high school in the United Stated between 1910 and 1940 (Goldin and Katz 1999). Moreover, our theoretical mechanism is supported by recent findings on the political economy of education expenditure in developing countries. A growing consensus in the literature recognizes that underinvestment in public education stems not only from supply-side problems such as government inability to fund and staff effective schools, but also from demand-side failures. Citizens routinely misunderstand what education can and should achieve. They misperceive the returns to schooling and signally underestimate the returns to primary education. Such misperception induces costly distortions in their demand for education (Jensen 2010; Banerjee and Duflo 2011; Bursztyn 2016).

Better information helps rectify these distortions at the individual level (Jensen 2010). In the aggregate, Reinikka and Svensson (2004, 2005) find that more informed voters hold local governments more accountable and ensure that education expenditure is higher and more effective. Conversely, where voters are uninformed, their evidence from Africa shows that central-government grants earmarked for primary schooling is overwhelmingly diverted to other uses by local officials. ${ }^{11}$ Reinikka and Svensson (2004) show that under-provision

\footnotetext{
${ }^{11}$ Empirically, it is unclear if the captured transfers are reallocated to other government spending programs that local politicians find more popular. It may be more likely that bureaucrats and politicians illegitimately appropriate them. Theoretically, it would be straightforward to extend our model to include a third category of government spending that only incumbent politicians benefit from. Then better monitoring by voters with higher social capital would also reduce political rent extraction, implying an even higher effect on public investment in education and on economic growth.
} 
of public investment in education is mitigated in areas with a higher socioeconomic status, which is broadly consistent with the role of social capital established in our model.

Reinikka and Svensson (2005) focus instead on newspaper readership as a source of voters' information. The role of the media in increasing accountability and improving policy outcomes is also well documented beyond education policy, for government interventions that range from disaster relief (Besley and Burgess 2002; Eisensee and Strömberg 2007) to trade policy (Ponzetto 2011), as well as for politicians' individual effort (Snyder and Strömberg 2010).

Our theoretical framework explicitly accounts for these empirical findings: exogenous individual information acquisition from outside the social network raises education spending $(\partial \zeta / \partial p<0)$. However, our model crucially highlights that social capital is always another determinant of political accountability and human-capital investment. For any rate of external information acquisition, higher social diffusion of information improves voter knowledge and the allocation of public expenditure $(\partial \theta / \partial q>0>\partial \zeta / \partial q$ for all $p<\infty) .{ }^{12}$

Unlike the expenditure decisions, the politician's choice of a tax rate is not directly affected by political-agency considerations. In our model, politicians do not have ideological preferences for raising or lowering taxes, nor do they intrinsically prefer overseeing a larger or smaller budget. Their only motivations are welfare maximization and career concerns. To improve his prospects of re-election, the incumbent tries to demonstrate his skill. The tax rate is unaffected by these incentives because it does not signal competence, nor does it change the inference of competence from the observed realization of public-good provision, conditional on the taxes that all voters pay and thus correctly perceive.

In the equilibrium described by Proposition 2, the misallocation of government expenditure also generates no indirect effects on taxation. Both the tax rate $\tau$, the total government budget $\left(x_{t}^{g}+x_{t}^{h}\right) / y_{t}$, and the output shares of private consumption $c_{t} / y_{t}$ and private investment in physical capital $k_{t+1} / y_{t}$ are invariant at their first-best levels described by Proposition 1. The political-economy distortion to the amount of public investment does not propagate to private-sector decisions because of the log-linear structure of preferences and technology, which implies unit elasticity of substitution between private and public investment. ${ }^{13}$

\footnotetext{
${ }^{12}$ Moreover, Putnam (1993) argues that newspaper readership is itself a proxy for social capital, on the grounds that social capital promotes civic engagement and leads individuals to pay closer attention to events in their community, and to politics in particular.

${ }^{13}$ Assuming an elasticity of substitution above unity could be more realistic. Besley and Persson's (2011) analysis of the origins of state capacity shows that fiscal capacity goes hand in hand with cohesive political institutions that promote the common interest. This finding suggests that equilibrium demand for the public sector is effectively elastic: the size of government expands when the government more efficiently pursues public welfare. Qualitatively, this alternative assumption would strengthen our result that the share of output devoted to public investment rises with social capital. Quantitatively, however, it would preclude an analytical solution of the model, as is well known from the real business cycle literature.
} 
In addition to distorting the size of government investment in education, lower visibility of the returns to public education expenditure reduces its productivity by distorting the selection of politicians. In principle, voters are keen on re-electing incumbents whose competence at providing all types of public goods is high. In practice, they cannot reward productivity in managing public investment if they have failed to notice it. Rational expectations allow citizens to anticipate exactly the equilibrium allocation of government expenditure. Thus, the direct observation of public-service provision $g_{t}$ enables all voters to infer with certainty the true realization of the innovation $\varepsilon_{t}^{g}$. Analogously, knowledge of the returns to public investment $h_{t+1}$ yields perfect inference about the realization of $\varepsilon_{t}^{h}$. However, this knowledge belongs only to a subset of the electorate, the larger the higher social capital.

In equilibrium, as in the first best, the incumbent's re-election $\chi_{t}$ is independent of the initial state of the economy $s_{t}$ and determined exclusively by the realized competence innovations $\varepsilon_{t}^{g}$ and $\varepsilon_{t}^{h}$. However, the importance of the latter is sub-optimally weighted by its visibility $\theta(p, q)$, so that re-election $\left(\chi_{t}=1\right)$ occurs if and only if

$$
\Psi_{t} \leq \gamma \varepsilon_{t}^{g}+\frac{(1-\alpha) \beta}{1-\beta} \theta \varepsilon_{t}^{h}
$$

In a sense, lack of information makes citizens more cynical about politicians' competence at providing public education. Uninformed voters are rationally disillusioned about the differences between rival candidates, whose competence in managing public education they perceive as identical. Thus, their voting decision is swayed instead by random popularity shocks that are pure noise.

Higher social capital enables citizens to share more effectively their knowledge of government competence. As a consequence, elections become a more effective screening mechanism. This theoretical result is consistent with empirical evidence that social capital raises voters' propensity to dismiss politicians who perform poorly or misbehave in office (Nannicini et al. 2013). The value of social capital as a driver of the selection of better politicians is captured by the last term of the welfare function $V\left(s_{t}\right)$. Intuitively, screening for high ability in the provision of public investment is more valuable the more heterogeneous the skill distribution $\left(\partial V / \partial \sigma_{h}^{2}>0\right)$. In turn, this raises the welfare benefits of social capital $\left(\partial^{2} V / \partial q \partial \sigma_{h}^{2}>0\right) .{ }^{14}$

The same two distortions that drive a wedge between equilibrium welfare $V\left(s_{t}\right)$ in Proposition 2 and the first best $V^{*}\left(s_{t}\right)$ in Proposition 1 also entail a different growth path for the economy in the dynamic equilibrium with imperfect political agency.

\footnotetext{
${ }^{14}$ Comparing $V\left(s_{t}\right)$ and $V^{*}\left(s_{t}\right)$ also shows that first-best electoral screening is not attained even with perfectly informed voters $(q \rightarrow \infty)$. Voters remain subject to random shocks $\Psi_{t}$ such that even the worst incumbent stands a chance of winning the election and the best of losing it on a wave of unpredictable popularity, independent of competence.
} 
Proposition 3 The economy follows a stochastic balanced growth path. The growth rate is:

$$
\log y_{t+1}-\log y_{t}=\alpha \log \alpha+(1-\alpha) \log \left(1-\alpha-\frac{\zeta}{\beta}\right)+\log A+\log \beta+(1-\alpha) \hat{\eta}_{t}^{h},
$$

where the equilibrium competence of the ruling politician is:

$$
\hat{\eta}_{t}^{h}=\chi_{t-1}\left(\varepsilon_{t-1}^{h}+\varepsilon_{t}^{h}\right)+\left(1-\chi_{t-1}\right)\left(\omega_{t-1}^{h}+\omega_{t}^{h}\right),
$$

such that $\mathbb{E}_{t} \hat{\eta}_{t}^{h}>0$.

Higher social capital $q$ increases the growth rate of output in the sense of first-order stochastic dominance. It also reduces the variance of the output growth rate.

In equilibrium, as in the first best, the economy reaches immediately a stochastic balanced growth path. However, a comparison with Corollary 1 establishes that the growth rate lags systematically behind the first best, and is the farther from it the lower the level of social capital. As we discussed in Proposition 2, voters' lack of information distorts both politicians' incentives and their selection. It reduces below their optimal levels both the amount of public investment in human capital and the equilibrium productivity of government spending on education. The greater social diffusion of information that results from higher social capital improves both the allocation of output and electoral screening. Each of these channels induces an upward shift in trend growth. Thus, our model provides a theoretical explanation for Algan and Cahuc's (2010) finding that social capital had a significant causal impact on worldwide growth during the twentieth century.

Proposition 3 concludes by establishing an intuitive effect of better electoral screening on the volatility of output. When more voters are aware of the returns to public investment, politicians who are less effective at providing it are more likely to be replaced. This selection essentially acts as a truncation of the left tail of the distribution of ability. As a consequence, the variance of the growth rate, which coincides with the variance of the government's investment productivity shock, tends to decline unless the distribution of innovation is strongly positively skewed. A positive skew tends to counteract the decline in variance, because higher social capital induces greater retention of incumbents with ability in the right tail. However, the negative effect prevails even for a modest positive skew, and a fortiori for our baseline assumption of a symmetric distribution of innovations. Therefore, we should expect higher levels of social capital and the ensuing better monitoring of politicians to lower the volatility of output growth as well as increasing its average. This theoretical prediction of our model is supported by the empirical finding of a negative correlation between trust and the standard deviation of the growth rate of real GDP per capita (Sangnier 2013). 


\section{Empirical Evidence}

\subsection{Social Capital and Voter Knowledge}

One of the contributions of our model is to show theoretically how social capital improves government accountability by facilitating the social diffusion of political information. The predicted aggregate relationship between higher social capital and better political selection and incentives is confirmed by empirical evidence. In electoral districts with high social capital the electoral punishment of misbehaving politicians is considerably larger, and political misbehavior is accordingly less frequent (Nannicini et al. 2013; Padró i Miquel et al. 2015). In this section, we provide evidence of our theoretical prediction that higher social capital causes greater voter knowledge at the individual level, using data from the American National Election Studies (ANES, 1948-2012). This dataset contains well established measures of both social capital and voter information.

The first two ANES variables that we consider are the ability to name the candidates in a U.S. House race and the ability to recognize the incumbent from a list of candidates. The first is a dummy variable, Name Recall, which equals 1 if the respondent could recall the name of any candidates for the U.S. House race. The second variable, Name Recognition, is a dummy variable equal to 1 if the respondent could identify the incumbent from a list of the major party candidates for the U.S. House in their district. Additionally, we consider whether social capital is correlated with the respondents' willingness to describe or rate their U.S. House representative. Snyder and Strömberg (2010) interpret the ability to rate a politician as a proxy for both voter information and accountability, because knowing where a politician stands is a necessary condition to hold that politician accountable. ANES respondents were asked to place their House representative on a seven-point ideological scale. We code the dummy variable Ideological Rating to equal 1 if the respondent provided a rating, and zero if they answered they "don't know" or "don't recognize" the incumbent. Respondents were also asked to rate their feelings towards the incumbent on a scale from 0 to 100 . The dummy variable Thermometer Provided equals to 1 if such a rating was provided, and 0 if the respondent answered they "don't know where to rate" or "can't judge," or couldn't recognize the incumbent's name. Finally, following Snyder and Strömberg (2010), we code the dummy variable Preferences Provided as equal to 1 if the respondent mentioned at least one thing they liked or disliked about the incumbent House representative in their district, and zero if they said that they did not know anything about this candidate.

We focus on two measures of social capital. The first is trust in strangers, by far the most commonly used measure of social capital. Consistent with the coding in other surveys, Trust is a dummy variable that equals 1 if the respondent believes that "most people can 
be trusted." Our second measure is a variable that is much less standard but arguably captures more directly the social diffusion of information, as depicted by our theoretical model. Talking with People is a dummy variable that equals 1 if the respondent reported discussing politics with family and friends.

We summarize our ANES variables in Table 1. The last two variables are dummies for the respondent's educational attainment, with high-school graduates without a BA degree as the omitted category. Tables 2 and 3 present our results. All the correlations presented in the tables control for survey year fixed effects and for the following pre-determined variables: gender, race and ethnicity, and age deciles. ${ }^{15}$ We present the coefficient of each correlation both when we do not control for education, and conditional on controls for educational attainment. Education may not be pre-determined to social capital, and, hence, the coefficients may be biased - typically downward.

As we can see from Tables 2 and 3, social capital is positively correlated with all measures of information and willingness to describe or rate politicians. The correlation is equally strong when proxying for social capital with the more standard measure, or with the one more closely related to our theoretical model. The coefficients are also economically significant. For instance, an increase in trust by one standard deviation increases the probability of recognizing the incumbent representative by about 0.14 standard deviations. Consistent with our theory, these results suggest a relationship between social capital, the interpersonal diffusion of political information, and citizens' knowledge about their government.

\subsection{Social Capital and Public Education Spending}

The main contribution of our model is to show theoretically how social capital raises the long-run output growth rate and reduces its volatility by improving political screening and incentives for investment in public education. The positive effect of social capital on economic growth has been extensively documented (Knack and Keefer 1997; Zak and Knack 2001; Tabellini 2009; Algan and Cahuc 2010; Gennaioli et al. 2013). Empirical evidence also supports our theoretical prediction of a negative correlation between social capital and the standard deviation of the growth rate of real GDP per capita (Sangnier 2013). In this section, we provide macroeconomic evidence of the specific channel predicted by our theory: across countries, government expenditure on education is increasing in social capital.

We measure social capital by the country-level average of the responses to questions in the World Values Survey Integrated Questionnaire 1981-2014. As in our individual-level analysis, we consider first the standard question asking respondents if "most people can be

\footnotetext{
${ }^{15}$ The results when we do not control for any pre-determined variable are virtually unchanged, and still statistically significant at the 1 percent level.
} 
trusted" or instead "you can't be too careful with people." In addition, we also use a second measure based on whether respondents reported that one of the "sources to learn what is going on in their country and the world" they used in the previous week was "talking with friends or colleagues." This measure reduces our number of observations because it has been included in the survey less frequently. On the other hand, it may be closer to capturing our theoretical definition of social capital as the potential for the social diffusion of information.

Across countries, public spending on education is indeed positively correlated with both measures of social capital, as predicted by our model. Figure 1 shows the correlation with trust in strangers and Figure 2 with the share of people who acquire information by talking to others. ${ }^{16}$ These correlations are robust to controlling for plausibly exogenous demographic and geographic characteristics: population, ethnic fractionalization, average distance to the nearest coast, and temperature. ${ }^{17}$ They are also robust to controlling for aggregate government spending as a share of GDP, which is independent of social capital in our model, although its exogeneity may be more questionable empirically. ${ }^{18}$

We summarize our macroeconomic variables in Table 4 . Table 5 presents our multivariate regression results. The empirical relationship between social capital and government investment in human capital is highly significant, both statistically and economically. In the specification with controls, an increase in social capital by one standard deviation is associated with an increase in public spending on education by approximately 0.34 standard deviations if we measure social capital by trust, and by 0.37 standard deviations if we measure it by information acquisition via talking to people.

Evidence supporting the theoretical predictions of our model is robust across different proxies of social capital. Yet, these consistent correlations do not suffice to establish a causal link between social capital and public spending on education. To alleviate endogeneity concerns, we need an instrumental variable that is correlated with social capital and affects government expenditure on education only through social capital.

Research in linguistics suggest that systematic patterns in languages may offer a window into their speakers' dispositions. Some components of language may have had an independent effect on specific cultural dimensions (Boroditsky 2000; Ozgen and Davies 2002; Zhou et al. 2010). In particular, languages that forbid dropping the subject personal pronouns are

\footnotetext{
${ }^{16}$ In unreported results, we find that public spending of education is also positively correlated with other measures of people's information, such as acquiring information from newspapers or media reports. These correlations support our ancillary theoretical prediction of a positive effect of external information supply $(p)$. They may also support the view that social capital promotes public education spending by inducing higher individual demand for information (Putnam 1993).

${ }^{17}$ The choice of these controls follows Gennaioli et al. (2013).

${ }^{18}$ We are unable to control for broader political and economic outcomes because of our limited number of observations and the lack of good instruments for such variables, which are endogenous to social capital.
} 
associated with cultures that give more emphasis to the individual relative to the social context (Kashima and Kashima 1998). Licht, Goldschmidt and Schwartz (2007) and Tabellini (2008) use variation in this linguistic dimension as an instrument for social capital.

More broadly, the causal impact of language on economic outcomes is receiving growing attention. Givati and Troiano (2012) exploit gender-differentiated personal pronouns as a pre-determined instrument for attitudes toward women. Chen (2013) finds that differentiation of verbal forms for the present and the future influences savings behavior through a discount-rate framing mechanism. The strongest reading of these findings is through the lens of linguistic relativity, which holds that language causally affects people's thought patterns. This theory, also known as the Sapir-Whorf hypothesis, is highly controversial among linguists and remains the object of an unresolved debate in linguistics and psychology (Masharov and Fischer 2006). However, the validity of language instruments does not hinge on a strict relativist interpretation. Even if language does not directly cause cultural attitudes, at least it reflects persistent cultural traits that have coevolved with language in the long run - typically over several centuries. As a consequence, linguistic patterns provide an effective instrument to address reverse causation and short-run confounds.

Following Tabellini (2008), we exploit grammatical rules on pronoun dropping to alleviate some of the causality concerns with our cross-country analysis. We instrument social capital with the grammar of the language most widely spoken in each country. ${ }^{19}$ This instrumental strategy satisfies the orthogonality restriction if pronoun dropping and the distant cultural forces that were responsible for its evolution are uncorrelated with unobserved determinants of public spending on education today.

Table 6 presents the results of this robustness check. Columns (1), (3) and (5) show the first stage equations. In the specifications with controls, grammar is a weak instrument for information acquisition via talking to people, with a first-stage $F$-statistic below 10 . Since the 2SLS estimator performs poorly with weak instruments, in this case we implement our instrumental-variable specification by limited information maximum likelihood estimation. In column (2) we confirm the strong, statistically significant positive correlation between social capital, now instrumented with our linguistic instrument, and public spending on education. In column (4) we confirm that the result continues to hold with geographic and demographic controls. Column (6) shows that the result is also robust to controlling for the overall size of government.

\footnotetext{
${ }^{19}$ We adopt Tabellini's (2008) weighting strategy for multilingual countries. Thus, the instrument coincides with the share of speakers of languages that allow omission of the subject pronoun, relative to the total number of speakers of all languages whose grammatical rules are coded by Kashima and Kashima (1998).
} 


\section{Conclusion}

Social capital promotes economic development. This robust empirical connection and its causal nature are well established. However, the precise channels that underpin it remain underexplored. In this paper, we have provided a novel theory and new evidence of one important mechanism. Social capital raises economic growth by inducing greater and more productive public investment in human capital.

Our model defined social capital as the ability to acquire information through interpersonal relationships. We have shown that when the social diffusion of information is greater more people learn about government effectiveness at providing public education, even though its delayed returns make it relatively hard to assess. As a result, greater social capital makes politicians less likely to win re-election when their skills and their spending are suboptimally skewed towards more visible short-run public services. In the dynamic stochastic general equilibrium, social capital raises the endogenous average growth rate because it mitigates the myopic populist temptation to underinvest in public education. Moreover, it lowers the endogenous volatility of output growth because it ensures that politicians whose poor competence would harm human-capital accumulation are more reliably removed from office.

Our empirical analysis has shown that the distinctive predictions of our theory are supported by evidence at both the individual and the aggregate level. Individuals with greater social capital have higher interest in and better knowledge of politics. Countries with greater social capital allocate a higher share of GDP to public investment in education. These correlations are robust to alternative proxies for social capital, including grammatical characteristics of a country's language that provide a strongly predictive instrument and plausibly alleviate endogeneity concerns.

Evidence both across countries and across regions suggests that the mechanism we have proposed can account for a substantial fraction of the effect of social capital on growth (Gennaioli et al. 2013). Nonetheless, this paper is undoubtedly closer to a first step than a final word in the study of the transmission mechanisms that connect social capital to economic development. We conclude by pointing out three directions for future work that seem particularly interesting in light of our analysis.

First, our model has shown that the social diffusion of information improves political incentives and political selection by making citizens better at monitoring their government. We have focused on the ensuing increase in public education spending because underinvestment in human capital is one of the fundamental problems in the political economy of development. However, our analysis suggests that social capital may also induce other pro-growth policies, such as better protection of property rights, or better regulation of entry or of finan- 
cial markets. Social capital may even induce more inclusive institutions by helping people to work together for democracy, like human capital does (Glaeser, Ponzetto and Shleifer 2007).

At the same time, we should be mindful of the demonstrated potential for social capital to induce instead welfare-decreasing outcomes (Acemoglu, Reed and Robinson 2014; Satyanath, Voigtländer and Voth 2017). Our model has not captured this dark side of social capital because we have abstracted from any heterogeneity. It is unambiguously beneficial for the representative citizen to have greater social connectedness. In our framework, however, if some citizens had greater social capital than everyone else they would gain disproportionate influence over the government. Inequality in the social diffusion of information would then induce detrimental policy distortions, like inequality in voter information does more broadly (Majumdar, Mani and Mukhand 2004; Glaeser and Ponzetto 2014). Our cross-country data provide some support for this intuition. If we regress spending on education not only on a country's average social diffusion of information, but also on its standard deviation across regions within the country, we obtain the following results:

$$
\text { Education Spending }=\underset{(1.75)}{2.96} \times \text { Talk with People }-\underset{(3.32)}{6.13} \times \sigma(\text { Talk with People })
$$

Both coefficients are significant at the $10 \%$ level. ${ }^{20}$ While no more than suggestive, this evidence is consistent with sociologists' long-standing concerns about the negative consequences of inequality in social capital (Bourdieu 1986; Lin 2001).

Finally, in this paper we have modeled a one-way impact of social capital on humancapital accumulation. This perspective is consistent with the typical view of social capital as a highly persistent, largely inherited cultural characteristic (Putnam 1993; Algan and Cahuc 2010). Yet, there is some empirical evidence of a reverse effect of education on social capital (Goldin and Katz 1999; Algan, Cahuc and Shleifer 2013). Such two-way causation would imply the potential for a growth trap with mutually reinforcing low levels of both social and human capital. Most important, it would suggest that a sufficiently large positive education shock could break an unfavorable legacy of poor culture and poor institutions, and set a country on a virtuous cycle of self-sustaining improvements in social connectedness, political quality and economic development (Glaeser et al. 2004).

\footnotetext{
${ }^{20}$ The regression has 45 observations and an $R^{2}$ of .430 . The dependent variable is the same as in Table 5 , and the controls are those of its column (3): government spending, population (log), number of ethnic groups (log), inverse distance to the coast, temperature. On the right-hand side, Talk with People is a dummy variable that equals 1 if a WVS respondent (1981-2008) reported that one of the "sources to learn what is going on in their country and the world" they used in the previous week was "talking with friends or colleagues." We compute its variance across regions because the variance across individuals is not separately defined from the mean for a dummy variable. Using the same procedure for Trust, we do not find a significant effect of its cross-region variance, but the positive effect of its countrywide average remains robust.
} 


\section{References}

[1] Acemoglu, Daron, Tristan Reed and James Robinson. 2014. "Chiefs: Economic Development and Elite Control of Civil Society in Sierra Leone." Journal of Political Economy 122(2): 319-368.

[2] Alesina, Alberto, and Guido Tabellini. 2008. "Bureaucrats or Politicians? Part II: Multiple Policy Tasks." Journal of Public Economics 92(3-4): 426-447.

[3] Alesina, Alberto, Arnaud Devleeschauwer, William Easterly, Sergio Kurlat and Romain Wacziarg. 2003. "Fractionalization." Journal of Economic Growth 8(2): 155-194.

[4] Alesina Alberto, John Londregan and Howard Rosenthal. 1993. "A Model of the Political Economy of the United States." American Political Science Review 87(1): 12-33.

[5] Alesina, Alberto, and Howard Rosenthal. 1995. Partisan Politics, Divided Government, and the Economy. Cambridge: Cambridge University Press.

[6] Alesina, Alberto, Nouriel Roubini and Gerald D. Cohen. 1997. Political Cycles and the Macroeconomy. Cambridge, MA: MIT Press.

[7] Algan, Yann, and Pierre Cahuc. 2010. "Inherited Trust and Growth." American Economic Review 100(5): 2060-2092.

[8] Algan, Yann, Pierre Cahuc and Andrei Shleifer. 2013. "Teaching Practices and Social Capital." American Economic Journal: Applied Economics 5(3): 189-210.

[9] Banerjee, Abhijit V., and Esther Duflo. 2011. Poor Economics: A Radical Rethinking of the Way to Fight Global Poverty. New York, NY: Public Affairs.

[10] Barro, Robert. 1990. "Government Spending in a Simple Model of Endogenous Growth." Journal of Political Economy 98(5): S103-S125.

[11] Barro, Robert. 1991. "Economic Growth in a Cross-Section of Countries." Quarterly Journal of Economics 106(2): 407-443.

[12] Bass, Frank M. 1969. "A New Product Growth Model for Consumer Durables." Management Science 15(5): 215-227.

[13] Beck, Paul A., Russell J. Dalton, Steven Greene and Robert Huckfeldt. 2002. "The Social Calculus of Voting: Interpersonal, Media, and Organizational Influences on Presidential Choices." American Political Science Review 96(1): 57-73. 
[14] Besley, Timothy, and Robin Burgess. 2002. "The Political Economy of Government Responsiveness: Theory and Evidence from India." Quarterly Journal of Economics 117(4): 1415-1451.

[15] Besley, Timothy, and Torsten Persson. 2011. Pillars of Prosperity: The Political Economics of Development Clusters. Princeton, NJ: Princeton University Press.

[16] Boffa, Federico, Amedeo Piolatto and Giacomo A. M. Ponzetto. 2016. "Political Centralization and Government Accountability." Quarterly Journal of Economics 131(1): $381-422$.

[17] Boroditsky, Lera. 2000. "Metaphoric Structuring: Understanding Time Through Spatial Metaphors." Cognition 75(1): 1-28.

[18] Bourdieu, Pierre. 1986. "The Forms of Capital." in Handbook of Theory and Research for the Sociology of Education, edited by John G. Richardon. Westport, CT: Greenwood Press.

[19] Bourlès, Renaud, Yann Bramoullé and Eduardo Perez-Richet. 2017. "Altruism in Networks." Econometrica 85(2): 675-689.

[20] Bowles Samuel and Herbert Gintis. 2002. "Social Capital and Community Governance." Economic Journal 112(483): F419-F436.

[21] Bursztyn, Leonardo. 2016. "Poverty and the Political Economy of Public Spending: Evidence from Brazil." Journal of the European Economic Association 14(5): 11011128.

[22] Castelfranchi, Cristiano, Rino Falcone and Francesca Marzo. 2006. "Being Trusted in a Social Network: Trust as Relational Capital." In Trust Management, edited by Ketil Stølen, William H. Winsborough, Fabio Martinelli and Fabio Massacci. Berlin: Springer.

[23] Chen, Keith. 2013. "The Effect of Language on Economic Behavior: Evidence from Savings Rates, Health Behaviors, and Retirement Assets." American Economic Review 103(2): 690-731.

[24] Chetty, Raj, John N. Friedman, Nathaniel Hilger, Emmanuel Saez, Diane Schanzenbach and Danny Yagan. 2011. "How Does Your Kindergarten Classroom Affect Your Earnings? Evidence from Project STAR." Quarterly Journal of Economics 126(4): 1593-1660.

[25] Cialdini, Robert. 1984. Influence: The Psychology of Persuasion. New York, NY: Quill. 
[26] Coate, Steven T., and Stephen E. Morris. 1995. "On the Form of Transfers to Special Interests." Journal of Political Economy 103(6): 1210-1235.

[27] Coleman, James S. 1988. "Social Capital in the Creation of Human Capital" American Journal of Sociology 94(Supplement): S95-S120.

[28] Cunha, Flavio, and James J. Heckman. 2008. "Formulating, Identifying and Estimating the Technology of Cognitive and Noncognitive Skill Formation." Journal of Human Resources 43(4): 738-782.

[29] Doepke, Matthias, and Fabrizio Zilibotti. 2008. "Occupational Choice and the Spirit of Capitalism." Quarterly Journal of Economics 123(2): 747-793.

[30] Durlauf, Steven N., and Marcel Fafchamps. 2005. "Social Capital." In Handbook of Economic Growth, Volume 1B, edited by Philippe Aghion and Steven N. Durlauf Amsterdam: Elsevier.

[31] Eisensee, Thomas, and David Strömberg. 2007. "News Droughts, News Floods and U.S. Disaster Relief." Quarterly Journal of Economics 122(2): 693-728.

[32] Fukuyama, Francis. 1995. Trust: Social Virtues and the Creation of Prosperity. London: Hamish Hamilton.

[33] Gallup, John Luke, Jeffrey D. Sachs and Andrew D. Mellinger. 1999. "Geography and Economic Development." International Regional Science Review 22(2): 179-232.

[34] Galor, Oded, and Omer Moav. 2002. "Natural Selection and the Origin of Economic Growth." Quarterly Journal of Economics 117(4): 1133-1191.

[35] Gennaioli, Nicola, Rafael La Porta, Florencio Lopez-de-Silanes and Andrei Shleifer. 2013. "Human Capital and Regional Development." Quarterly Journal of Economics 128(1): 105-164.

[36] Givati, Yehonatan, and Ugo Troiano. 2012. "Law, Economics and Culture: Theory of Mandated Benefits and Evidence from Maternity Leave Policies." Journal of Law and Economics 55(2): 339-364.

[37] Glaeser, Edward L., David I. Laibson and Bruce Sacerdote. 2002. "An Economic Approach to Social Capital." Economic Journal 112(483): 437-458.

[38] Glaeser, Edward L., David I. Laibson, José A. Scheinkman and Christine L. Soutter. 2000. "Measuring Trust." Quarterly Journal of Economics 115(3): 811-846. 
[39] Glaeser, Edward L., Rafael La Porta, Florencio Lopez-de-Silanes and Andrei Shleifer. 2004. "Do Institutions Cause Growth?" Journal of Economic Growth 9(3): 271-303.

[40] Glaeser, Edward L., and Giacomo A. M. Ponzetto. 2014. "Shrouded Costs of Government: The Political Economy of State and Local Public Pensions." Journal of Public Economics 116: 89-105.

[41] Glaeser, Edward L., Giacomo A. M. Ponzetto and Andrei Shleifer. 2007. "Why Does Democracy Need Education?" Journal of Economic Growth 12(1): 77-99.

[42] Goldin, Claudia, and Lawrence F. Katz. 1999. "Human Capital and Social Capital: The Rise of Secondary Schooling in America, 1910 to 1940." Journal of Interdisciplinary History 29(4): 683-723.

[43] Gorodnichenko, Yuriy, and Gerard Roland. 2017. "Culture, Institutions and the Wealth of Nations." Review of Economics and Statistics 99(3): 402-416.

[44] Granovetter, Mark. 1973. "The Strength of Weak Ties." American Journal of Sociology 78(6): 1360-1380.

[45] Greif, Avner. 2006. Institutions and the Path to the Modern Economy: Lessons from Medieval Trade. Cambridge: Cambridge University Press.

[46] Guiso, Luigi, Paola Sapienza and Luigi Zingales. 2004. "The Role of Social Capital in Financial Development." American Economic Review 94(3): 526-56.

[47] —. 2011. "Civic Capital as the Missing Link." In Handbook of Social Economics, Volume 1A, edited by Jess Benhabib, Alberto Bisin and Matthew O. Jackson. Amsterdam: Elsevier.

[48] —. 2016. "Long Term Persistence." Journal of the European Economic Association 14(6): 1401-1436.

[49] Islam, T. M. Tonmoy, Jenny Minier and James P. Ziliak. 2015. "On Persistent Poverty in a Rich Country." Southern Economic Journal 81(3): 653-678.

[50] Jackson, Matthew O. 2010. Social and Economics Networks. Princeton, NJ: Princeton University Press.

[51] Jensen, Robert. 2010. "The (Perceived) Returns to Education and the Demand for Schooling." Quarterly Journal of Economics 125(2): 515-548. 
[52] Kashima, Emiko S., and Yoshihisa Kashima. 1998. "Culture and Language: The Case of Cultural Dimensions and Personal Pronoun Use." Journal of Cross-Cultural Psychology 29(3): 461-486.

[53] King, Robert G., Charles I. Plosser and Sergio T. Rebelo. 1988. "Production, Growth and Business Cycles: II. New Directions." Journal of Monetary Economics 21(2-3): 309-341.

[54] Knack, Stephen, and Philip Keefer. 1997. "Does Social Capital Have an Economic Payoff? A Cross-Country Investigation." Quarterly Journal of Economics 112(4): 12511288.

[55] Kumar, Krishna B., and John G. Matsusaka. 2009. "From Families to Formal Contracts: An Approach to Development." Journal of Development Economics 90(1): 106-119.

[56] La Porta, Rafael, Florencio Lopez-de-Silanes, Andrei Shleifer and Robert W. Vishny. 1997. "Trust in Large Organizations." American Economic Review 87(2): 333-338.

[57] Licht, Amir N., Chanan Goldschmidt and Shalom H. Schwartz. 2007. "Culture Rules: The Foundations of the Rule of Law and Other Norms of Governance. " Journal of Comparative Economics 35(4): 659-688.

[58] Lin, Nan. 2001. Social Capital: A Theory of Structure and Action. Cambridge: Cambridge University Press.

[59] Lindbeck, Assar, and Jörgen W. Weibull. 1987. "Balanced-Budget Redistribution as the Outcome of Political Competition." Public Choice 52(3): 273-297.

[60] Lindner, Ines and Holger Strulik. 2015. "From Tradition to Modernity: Economic Growth in a Small World." Journal of Development Economics 109: 17-29.

[61] Long, John B., and Charles I. Plosser. 1983. "Real Business Cycles." Journal of Political Economy 91(1): 36-69.

[62] Majumdar, Sumon, Anandi Mani and Sharun Mukand. 2004. "Politics, Information and the Urban Bias." Journal of Development Economics 75(1): 137-165.

[63] Mani, Anandi, and Sharun Mukand. 2007. "Democracy, Visibility and Public Good Provision." Journal of Development Economics 83(2): 506-529.

[64] Manuelli, Rodolfo E., and Ananth Seshandri. 2014. "Human Capital and the Wealth of Nations." American Economic Review 104(9): 2736-2762. 
[65] Masharov, Mikhail, and Martin H. Fischer. 2006. "Linguistic Relativity: Does Language Help or Hinder Perception?" Current Biology 16(8): 289-291.

[66] Nannicini, Tommaso, Andrea Stella, Guido Tabellini and Ugo Troiano. 2013. "Social Capital and Political Accountability." American Economic Journal: Economic Policy 5(2): 222-250.

[67] Ozgen, Emre, and Ian R. L. Davies. 2002. "Acquisition of Categorical Color Perception: A Perceptual Learning Approach to the Linguistic Relativity Hypothesis." Journal of Experimental Psychology 131(4): 477-493.

[68] Padró i Miquel, Gerard, Nancy Qian, Yiqing Xu and Yang Yao. 2015. "Making Democracy Work: Culture, Social Capital and Elections in China." NBER Working Paper No. 21058.

[69] Persson, Torsten, and Guido Tabellini. 1990. Macroeconomic Policy, Credibility and Politics. Chur: Harwood Academic Publishers.

[70] —. 2000. Political Economics: Explaining Economic Policy. Cambridge, MA: MIT Press.

[71] Ponzetto, Giacomo A. M. 2011. "Heterogeneous Information and Trade Policy." CEPR Discussion Paper No. 8726.

[72] Putnam, Robert D. 1993. Making Democracy Work: Civic Traditions in Modern Italy. Princeton, NJ: Princeton University Press.

[73] - 2000. Bowling Alone: The Collapse and Revival of American Community. New York, NY: Simon and Schuster.

[74] Reinikka, Ritva, and Jakob Svensson. 2004. "Local Capture: Evidence from a Central Government Transfer Program in Uganda." Quarterly Journal of Economics 119(2): 679-706.

[75] — 2005. "Fighting Corruption to Improve Schooling: Evidence from a Newspaper Campaign in Uganda." Journal of the European Economic Association 3(2-3): 259-267.

[76] Rogoff, Kenneth. 1990. "Equilibrium Political Budget Cycles." American Economic Review 80(1): 21-36.

[77] Rogoff, Kenneth, and Anne Sibert. 1988. "Elections and Macroeconomic Policy Cycles." Review of Economic Studies 55(1): 1-16. 
[78] Routledge, Bryan R., and Joachim von Amsberg. 2003. "Social Capital and Growth." Journal of Monetary Economics 50(1): 167-193.

[79] Sangnier, Marc. 2013. "Does Trust Favor Macroeconomic Stability? " Journal of Comparative Economics 41(3): 653-668.

[80] Satyanath, Shanker, Nico Voigtländer and Hans-Joachim Voth. 2017. "Bowling for Fascism: Social Capital and the Rise of the Nazi Party." Journal of Political Economy 125(2): 478-526.

[81] Shah, Anuj K., Sendhil Mullainathan and Eldar Shafir. 2012. "Some Consequences of Having Too Little." Science 338(6107): 682-685.

[82] Snyder, James M., and David Strömberg. 2010. "Press Coverage and Political Accountability." Journal of Political Economy 118(2): 335-408.

[83] Solow, Robert M. 1995. "But Verify - Trust: The Social Virtues and the Creation of Prosperity by Francis Fukuyama." The New Republic 213(11): 36-39.

[84] Strömberg, David. 2004. "Radio's Impact on Public Spending." Quarterly Journal of Economics 99: 189-221.

[85] Tabellini, Guido. 2008. "Institutions and Culture." Journal of the European Economic Association 6(2-3): 255-294.

[86] - 2009. "Culture and Institutions: Economic Development in the Regions of Europe." Journal of the European Economic Association 8(4): 677-716.

[87] Valenzuela, Sebastian, Namsu Park and Kerk Kee. 2009. "Is There Social Capital in a Social Network Site? Facebook Use and College students' Life Satisfaction, Trust and Participation." Journal of Computer-Mediated Communication 14(4): 875-901.

[88] Zak, Paul J., and Stephen Knack. 2001. "Trust and Growth." Economic Journal 111(470): 295-321.

[89] Zaller, John. 1992. The Nature and Origins of Mass Opinion. Cambridge: Cambridge University Press.

[90] Zhou, Ke, Lei Mo, Paul Kay, Veronica P. Y. Kwok, Tiffany N. M. Ip and Li Hai Tan. 2010. "Newly Trained Lexical Categories Produce Lateralized Categorical Perception of Color." Proceedings of the National Academy of Sciences 107(22): 9974-9978. 
Figure 1: Public Spending on Education and Trust

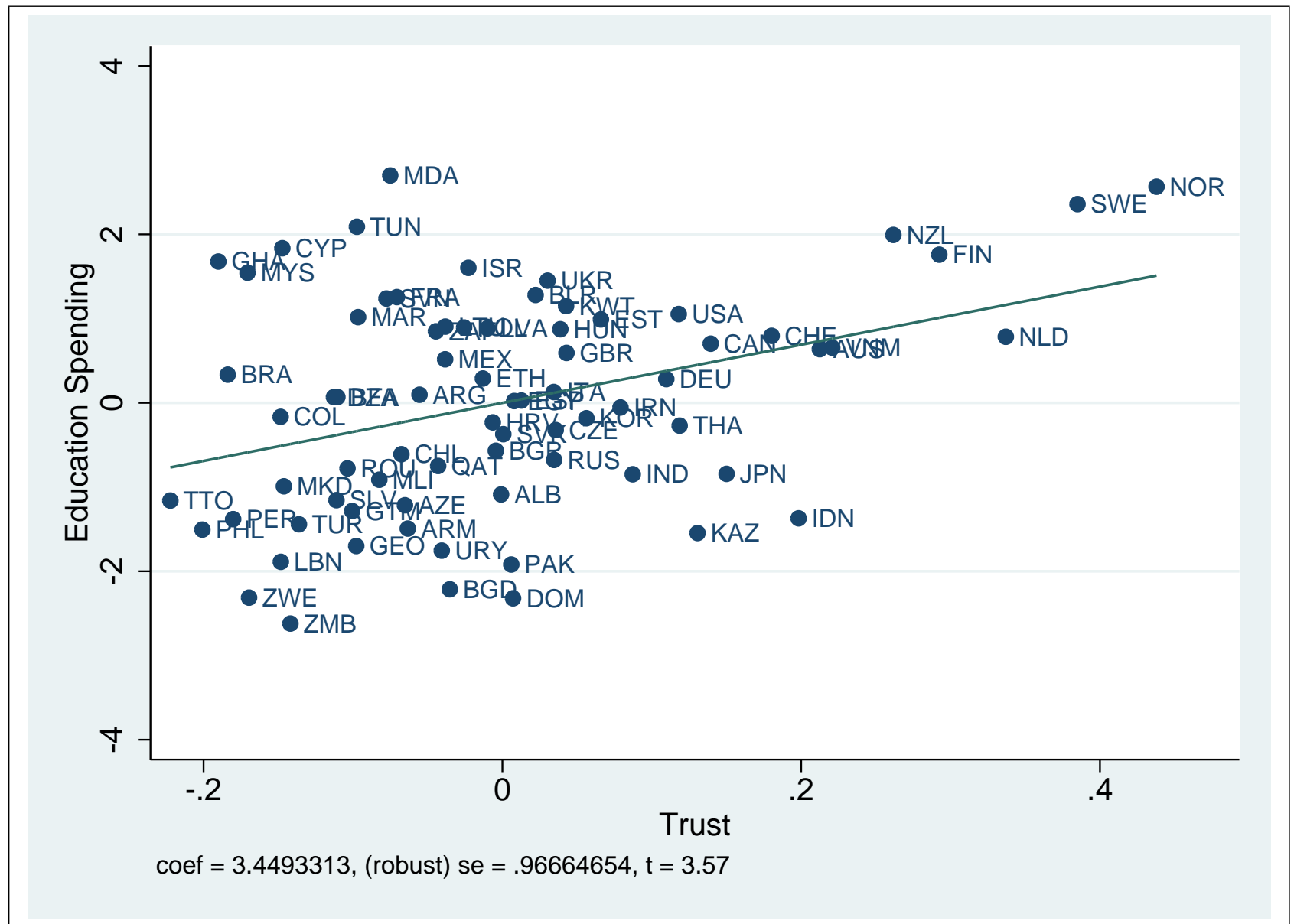

Notes: Partial correlation plot of government expenditure on education as a percentage of GDP ( average 2000-2010, from the World Development Indicators) and the fraction of World Values Survey respondents (1981-2014) who agree with the statement: "Most people can be trusted." 
Figure 2: Public Spending on Education and Talking with Other People

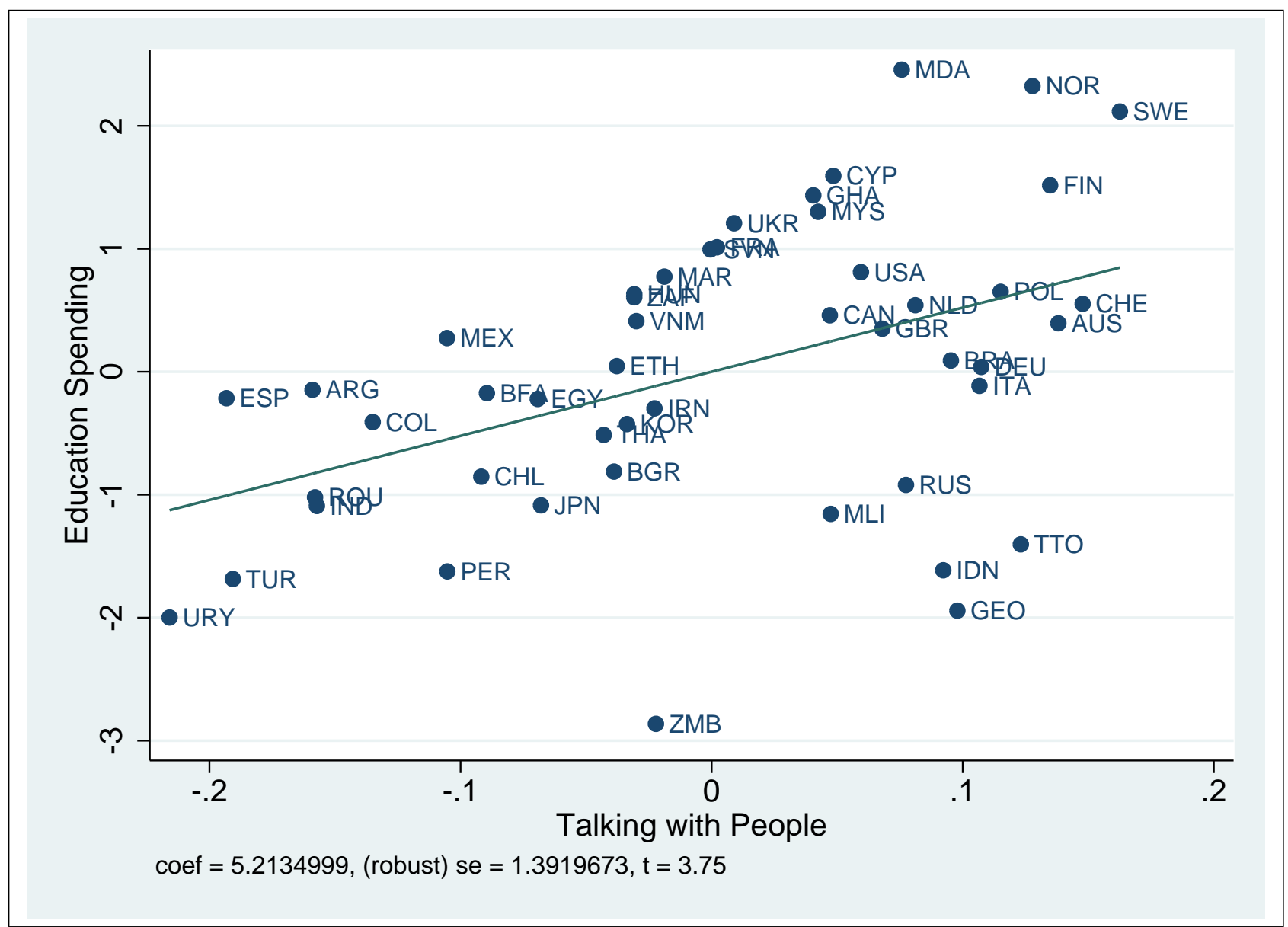

Notes: Partial correlation plot of government expenditure on education as a percentage of GDP (average 2000-2010, from the World Development Indicators) and the fraction of World Values Survey respondents (1981-2014) who report that one of the "sources to learn what is going on in their country and the world" they used in the previous week was "talking with friends or colleagues." 
Table 1: Summary Statistics - Micro Data

\begin{tabular}{lccccc}
\hline & Mean & Std. Dev. & Obs. & Min. & Max. \\
\hline Name Recall & .316 & .465 & 14,024 & 0 & 1 \\
Name Recognition & .620 & .485 & 17,777 & 0 & 1 \\
Ideological Rating & .689 & .463 & 9,484 & 0 & 1 \\
Thermometer Provided & .821 & .383 & 19,211 & 0 & 1 \\
Preferences Provided & .475 & .499 & 12,262 & 0 & 1 \\
Trust & .477 & .499 & 13,262 & 0 & 1 \\
Talking with People & .754 & .430 & 20,522 & 0 & 1 \\
Less than High School Degree & .197 & .398 & 25,015 & 0 & 1 \\
College Degree or More & .235 & .424 & 25,015 & 0 & 1 \\
\hline \hline
\end{tabular}

Notes: Data from the American National Election Studies, 1948-2012. Name Recall is a dummy variable equal to 1 if the respondent could recall the name of any candidate running for the U.S. House in their district. Name Recognition is a dummy variable equal to 1 if the respondent could identify the incumbent from a list of the major party candidates for the U.S. House in their district. Ideological Rating is a dummy variable equal to 1 if the respondent placed their U.S. House representative on a seven-point ideological scale, and 0 if they answered they "don't know" or "don't recognize" the incumbent. Thermometer Provided is a dummy variable equal to 1 if the respondent rated their feelings towards the incumbent on a scale from 0 to 100, and 0 if they answered they "don't know where to rate," or "can't judge," or couldn't recognize the incumbent's name. Preferences Provided is a dummy variable equal to 1 if the respondent mentioned at least one thing they liked or disliked about the incumbent U.S. House representative in their district, and 0 if they reported that they did not know anything about this candidate. Trust is a dummy variable equal to 1 if the respondent agreed with the statement: "Most people can be trusted." Talking with People is a dummy variable equal to 1 if the respondent reported discussing politics with family and friends. Less than High School Degree and College Degree or More are dummy variables for educational attainment. 
Table 2: Voter Information and Social Capital

\begin{tabular}{|c|c|c|c|c|}
\hline \multicolumn{5}{|l|}{ Panel A } \\
\hline & Name Recall & Name Recall & Name Recognition & Name Recognition \\
\hline Trust & $\begin{array}{l}.129^{* * *} \\
(.012)\end{array}$ & $\begin{array}{l}.076^{* * *} \\
(.012)\end{array}$ & $\begin{array}{l}.137^{* * *} \\
(.010)\end{array}$ & $\begin{array}{l}.095^{* * *} \\
(.010)\end{array}$ \\
\hline Less than High School & & $\begin{array}{l}-.148^{* * *} \\
(.015)\end{array}$ & & $\begin{array}{l}-.167^{* * *} \\
(.012)\end{array}$ \\
\hline College or More & & $\begin{array}{l}.196^{* * *} \\
(.014)\end{array}$ & & $\begin{array}{l}.096^{* * *} \\
(.011)\end{array}$ \\
\hline$R^{2}$ & .117 & .164 & .092 & .119 \\
\hline Observations & 6,258 & 6,258 & 10,082 & 10,082 \\
\hline \multicolumn{5}{|l|}{ Panel B } \\
\hline Talking with People & $\begin{array}{l}.192^{* * *} \\
(.008)\end{array}$ & $\begin{array}{l}.140^{* * *} \\
(.008)\end{array}$ & $\begin{array}{l}.219^{* * *} \\
(.010)\end{array}$ & $\begin{array}{l}.173^{* * *} \\
(.010)\end{array}$ \\
\hline Less than High School & & $\begin{array}{l}-.136^{* * *} \\
(.009)\end{array}$ & & $\begin{array}{l}-.166^{* * *} \\
(.011)\end{array}$ \\
\hline College or More & & $\begin{array}{l}.176^{* * *} \\
(.010)\end{array}$ & & $\begin{array}{l}.105^{* * *} \\
(.009)\end{array}$ \\
\hline$R^{2}$ & .119 & .159 & .114 & .140 \\
\hline Observations & 14,024 & 14,024 & 13,881 & 13,881 \\
\hline
\end{tabular}

Notes: $* \mathrm{p} \leq 0.1 ;{ }^{* *} \mathrm{p} \leq 0.05 ; * * * \mathrm{p} \leq 0.01$. Standard errors are corrected for White heteroskedasticity. Data from the American National Election Studies, 1948-2012. Name Recall is a dummy variable equal to 1 if the respondent could recall the name of any candidate running for the U.S. House in their district. Name Recognition is a dummy variable equal to 1 if the respondent could identify the incumbent from a list of the major party candidates for the U.S. House in their district. Trust is a dummy variable equal to 1 if the respondent agreed with the statement: "Most people can be trusted." Talking with People is a dummy variable equal to 1 if the respondent reported discussing politics with family and friends. Less than High School Degree and College Degree or More are dummy variables for educational attainment. All regressions include fixed effects for gender, race/ethnicity, age deciles and survey year. 
Table 3: Political Opinions and Social Capital

\begin{tabular}{|c|c|c|c|c|c|c|}
\hline \multicolumn{7}{|l|}{ Panel $A$} \\
\hline & $\begin{array}{l}\text { Ideological } \\
\text { Rating }\end{array}$ & $\begin{array}{l}\text { Ideological } \\
\text { Rating }\end{array}$ & $\begin{array}{l}\text { Thermometer } \\
\text { Provided }\end{array}$ & $\begin{array}{l}\text { Thermometer } \\
\text { Provided }\end{array}$ & $\begin{array}{l}\text { Preferences } \\
\text { Provided }\end{array}$ & $\begin{array}{c}\text { Preferences } \\
\text { Provided }\end{array}$ \\
\hline Trust & $\begin{array}{l}.084^{* * *} \\
(.014)\end{array}$ & $\begin{array}{l}.054^{* * *} \\
(.014)\end{array}$ & $\begin{array}{l}.059^{* * *} \\
(.008)\end{array}$ & $\begin{array}{l}.035^{* * *} \\
(.008)\end{array}$ & $\begin{array}{l}.115^{* * *} \\
(.014)\end{array}$ & $\begin{array}{l}.077^{* * *} \\
(.014)\end{array}$ \\
\hline Less than High School & & $\begin{array}{l}-.162^{* * * *} \\
(.024)\end{array}$ & & $\begin{array}{l}-.151^{* * * *} \\
(.016)\end{array}$ & & $\begin{array}{l}-.143^{* * * *} \\
(.020)\end{array}$ \\
\hline College or More & & $\begin{array}{l}.091^{* * *} \\
(.015)\end{array}$ & & $\begin{array}{l}.050^{* * *} \\
(.008)\end{array}$ & & $\begin{array}{l}.124^{* * *} \\
(.015)\end{array}$ \\
\hline$R^{2}$ & .049 & .070 & .051 & .073 & .110 & .133 \\
\hline Observations & 4,751 & 4,751 & 8,305 & 8,305 & 5,339 & 5,339 \\
\hline \multirow{2}{*}{ Panel B } & & & & & & \\
\hline & $\begin{array}{l}\text { Ideological } \\
\text { Rating }\end{array}$ & $\begin{array}{l}\text { Ideological } \\
\text { Rating }\end{array}$ & $\begin{array}{l}\text { Thermometer } \\
\text { Provided }\end{array}$ & $\begin{array}{l}\text { Thermometer } \\
\text { Provided }\end{array}$ & $\begin{array}{l}\text { Preferences } \\
\text { Provided }\end{array}$ & $\begin{array}{c}\text { Preferences } \\
\text { Provided }\end{array}$ \\
\hline Talking with People & $\begin{array}{l}.157^{* * *} \\
(.012)\end{array}$ & $\begin{array}{l}.131^{* * *} \\
(.013)\end{array}$ & $\begin{array}{l}.108^{* * *} \\
(.007)\end{array}$ & $\begin{array}{l}.084^{* * *} \\
(.007)\end{array}$ & $\begin{array}{l}.223^{* * *} \\
(.010)\end{array}$ & $\begin{array}{l}.187^{* * *} \\
(.010)\end{array}$ \\
\hline Less than High School & & $\begin{array}{l}-.085^{* * *} \\
(.015)\end{array}$ & & $\begin{array}{l}-.118^{* * *} \\
(.010)\end{array}$ & & $\begin{array}{l}-.106^{* * *} \\
(.012)\end{array}$ \\
\hline College or More & & $\begin{array}{l}.076^{* * *} \\
(.011)\end{array}$ & & $\begin{array}{l}.044^{* * *} \\
(.006)\end{array}$ & & $\begin{array}{l}.111^{* * *} \\
(.011)\end{array}$ \\
\hline$R^{2}$ & .053 & .063 & .0357 & .071 & .112 & .135 \\
\hline Observations & 9,327 & 9,327 & 18,770 & 18,770 & 12,262 & 12,262 \\
\hline
\end{tabular}

Notes: ${ }^{*} \mathrm{p} \leq 0.1 ;{ }^{* *} \mathrm{p} \leq 0.05 ;{ }^{* *} \mathrm{p} \leq 0.01$. Standard errors are corrected for White heteroskedasticity. Data from the American National Election Studies, 1948-2012. Ideological Rating is a dummy variable equal to 1 if the respondent placed their U.S. House representative on a seven-point ideological scale, and 0 if they answered they "don't know" or "don't recognize" the incumbent. Thermometer Provided is a dummy variable equal to 1 if the respondent rated their feelings towards the incumbent on a scale from 0 to 100, and 0 if they answered they "don't know where to rate," or "can't judge," or couldn't recognize the incumbent's name. Preferences Provided is a dummy variable equal to 1 if the respondent mentioned at least one thing they liked or disliked about the incumbent U.S. House representative in their district, and 0 if they reported that they did not know anything about this candidate. Trust is a dummy variable equal to 1 if the respondent agreed with the statement: "Most people can be trusted." Talking with People is a dummy variable equal to 1 if the respondent reported discussing politics with family and friends. Less than High School Degree and College Degree or More are dummy variables for educational attainment. All regressions include fixed effects for gender, race/ethnicity, age deciles and survey year. 


\section{Table 4: Summary Statistics - Macro Data}

\begin{tabular}{lccccc}
\hline & Mean & Std. Dev. & Obs. & Min. & Max. \\
\hline Education Spending & 4.29 & 1.29 & 74 & 1.67 & 6.99 \\
Trust & .257 & .139 & 74 & .035 & .695 \\
Talking with People & .762 & .102 & 48 & .547 & .925 \\
Pronoun Drop & .676 & .471 & 49 & 0 & 1 \\
Government Spending & 25.10 & 10.24 & 74 & 2.07 & 55.42 \\
Population (log) & 16.68 & 1.52 & 74 & 13.83 & 20.86 \\
Number of Ethnic Groups $(\log )$ & 1.57 & 0.40 & 74 & 0.69 & 2.30 \\
Inverse Distance to Coast & .011 & .020 & 74 & .000 & .128 \\
Temperature & 14.66 & 8.61 & 74 & -7.14 & 28.30 \\
\hline \hline
\end{tabular}

Notes: Education Spending is government expenditure on education as a percentage of GDP, average 2000-2010, from the World Development Indicators. Trust is the share of World Values Survey respondents (1981-2014) who agree with the statement: "Most people can be trusted." Talking with People is the share of WVS respondents who report that one of the "sources to learn what is going on in their country and the world" they used in the previous week was "talking with friends or colleagues." Pronoun Drop is the population share of languages that allow the speaker to omit the subject personal pronoun in a sentence, from Tabellini (2008). Government Spending is total government expense as a percentage of GDP, average 2000-2010, from the WDI. Population (log) is the logarithm of the average number of residents, 2000-2010, from the WDI. Number of Ethnic Groups (log) is from Alesina et al. (2003). Inverse Distance to Coast is the inverse of the mean distance in $\mathrm{km}$ from the nearest ice-free coastline, from Gallup, Sachs and Mellinger (1999). Temperature is the annual mean temperature in degrees Celsius, 1961-1999, from the World Bank Climate Change Knowledge Portal. 


\section{Table 5: Public Spending on Education and Social Capital}

\begin{tabular}{|c|c|c|c|}
\hline \multicolumn{4}{|l|}{ Panel $A$} \\
\hline Trust & $\begin{array}{l}3.449^{* * *} \\
(0.967)\end{array}$ & $\begin{array}{l}3.120^{* * *} \\
(0.985)\end{array}$ & $\begin{array}{l}3.125^{* * *} \\
(0.886)\end{array}$ \\
\hline Government Spending & & & $\begin{array}{l}.057^{* * *} \\
(.014)\end{array}$ \\
\hline Population (log) & & $\begin{array}{l}-.117 \\
(.096)\end{array}$ & $\begin{array}{l}-.067 \\
(.094)\end{array}$ \\
\hline No. of Ethnic Groups (log) & & $\begin{array}{l}.133 \\
(.331)\end{array}$ & $\begin{array}{c}.207 \\
(.309)\end{array}$ \\
\hline Inverse Distance to Coast & & $\begin{array}{c}0.280 \\
(8.279)\end{array}$ & $\begin{array}{l}-6.227 \\
(5.116)\end{array}$ \\
\hline Temperature & & $\begin{array}{l}-.017 \\
(.017)\end{array}$ & $\begin{array}{c}.006 \\
(.016)\end{array}$ \\
\hline$R^{2}$ & .138 & .177 & .342 \\
\hline Observations & 74 & 74 & 74 \\
\hline \multicolumn{4}{|l|}{ Panel B } \\
\hline Talking with People & $\begin{array}{l}5.214^{* * *} \\
(1.392)\end{array}$ & $\begin{array}{l}5.193^{* * *} \\
(1.463)\end{array}$ & $\begin{array}{l}4.655^{* * *} \\
(1.619)\end{array}$ \\
\hline Government Spending & & & $\begin{array}{l}.052^{* * *} \\
(.014)\end{array}$ \\
\hline Population (log) & & $\begin{array}{l}-.120 \\
(.142)\end{array}$ & $\begin{array}{l}-.049 \\
(.135)\end{array}$ \\
\hline No. of Ethnic Groups (log) & & $\begin{array}{l}-.283 \\
(.323)\end{array}$ & $\begin{array}{c}-.104 \\
(.300)\end{array}$ \\
\hline Inverse Distance to Coast & & $\begin{array}{c}-9.595 \\
(10.422)\end{array}$ & $\begin{array}{c}-14.261^{* *} \\
(6.376)\end{array}$ \\
\hline Temperature & & $\begin{array}{l}-.013 \\
(.019)\end{array}$ & $\begin{array}{c}.006 \\
(.018)\end{array}$ \\
\hline$R^{2}$ & .202 & .257 & .388 \\
\hline Observations & 48 & 48 & 48 \\
\hline
\end{tabular}

Notes: $* \mathrm{p} \leq 0.1 ;{ }^{* *} \mathrm{p} \leq 0.05 ; * * * \mathrm{p} \leq 0.01$. Standard errors are corrected for White heteroskedasticity. The dependent variable is government expenditure on education as a percentage of GDP, average 2000-2010, from the World Development Indicators. Trust is the share of World Values Survey respondents (1981-2014) who agree with the statement: "Most people can be trusted." Talking with People is the share of WVS respondents who report that one of the "sources to learn what is going on in their country and the world" they used in the previous week was "talking with friends or colleagues." Government Spending is total government expense as a percentage of GDP, average 2000-2010, from the WDI. Population ( $\mathrm{log}$ ) is the logarithm of the average number of residents, 2000-2010, from the WDI. Number of Ethnic Groups (log) is from Alesina et al. (2003). Inverse Distance to Coast is the inverse of the mean distance in $\mathrm{km}$ from the nearest ice-free coastline, from Gallup, Sachs and Mellinger (1999). Temperature is the annual mean temperature in degrees Celsius, 1961-1999, from the World Bank Climate Change Knowledge Portal. 
Table 6: Public Spending on Education and Social Capital - IV Estimation

\begin{tabular}{|c|c|c|c|c|c|c|}
\hline \multicolumn{7}{|l|}{ Panel $A$} \\
\hline & $\begin{array}{c}\text { Trust } \\
\text { (1st Stage) }\end{array}$ & $\begin{array}{l}\text { Education } \\
\text { Spending } \\
\text { (2SLS) }\end{array}$ & $\begin{array}{c}\text { Trust } \\
\text { (1st Stage) }\end{array}$ & $\begin{array}{c}\text { Education } \\
\text { Spending } \\
\text { (2SLS) }\end{array}$ & $\begin{array}{c}\text { Trust } \\
\text { (1st Stage) }\end{array}$ & $\begin{array}{c}\text { Education } \\
\text { Spending } \\
\text { (2SLS) }\end{array}$ \\
\hline Trust & & $\begin{array}{l}8.805^{* * *} \\
(2.130)\end{array}$ & & $\begin{array}{l}10.518^{* * *} \\
(3.092)\end{array}$ & & $\begin{array}{l}8.743^{* * *} \\
(2.557)\end{array}$ \\
\hline Pronoun Drop & $\begin{array}{c}-.179^{* * *} \\
(.047)\end{array}$ & & $\begin{array}{c}-.153^{* * *} \\
(.048)\end{array}$ & & $\begin{array}{c}-.165^{* * *} \\
(.048)\end{array}$ & \\
\hline Government Spending & & & & & $\begin{array}{l}-.002 \\
(.002)\end{array}$ & $\begin{array}{l}.046^{* * *} \\
(.017)\end{array}$ \\
\hline Population (log) & & & $\begin{array}{c}.004 \\
(.013)\end{array}$ & $\begin{array}{l}-.127 \\
(.162)\end{array}$ & $\begin{array}{l}.000 \\
(.013)\end{array}$ & $\begin{array}{l}-.033 \\
(.131)\end{array}$ \\
\hline No. of Ethnic Groups (log) & & & $\begin{array}{l}-.067 \\
(.050)\end{array}$ & $\begin{array}{l}.509 \\
(.454)\end{array}$ & $\begin{array}{l}-.071 \\
(.050)\end{array}$ & $\begin{array}{l}.482 \\
(.402)\end{array}$ \\
\hline Inverse Distance to Coast & & & $\begin{array}{c}0.846 \\
(2.431)\end{array}$ & $\begin{array}{l}-10.155 \\
(21.682)\end{array}$ & $\begin{array}{c}1.097 \\
(2.580)\end{array}$ & $\begin{array}{c}-14.200 \\
(18.878)\end{array}$ \\
\hline Temperature & & & $\begin{array}{c}-.006^{* *} \\
(.002)\end{array}$ & $\begin{array}{c}.061 \\
(.039)\end{array}$ & $\begin{array}{c}-.006^{* *} \\
(.002)\end{array}$ & $\begin{array}{l}.060 \\
(.037)\end{array}$ \\
\hline$F$ stat. of excl. instruments & 15.12 & & 12.82 & & 14.55 & \\
\hline Observations & 49 & 49 & 49 & 49 & 49 & 49 \\
\hline Clusters (Languages) & 33 & 33 & 33 & 33 & 33 & 33 \\
\hline Panel B & $\begin{array}{c}\text { Talking } \\
\text { w/ People } \\
\text { (1st stage) }\end{array}$ & $\begin{array}{l}\text { Education } \\
\text { Spending } \\
\text { (2SLS) }\end{array}$ & $\begin{array}{c}\text { Talking } \\
\text { w/ People } \\
\text { (1st stage) }\end{array}$ & $\begin{array}{l}\text { Education } \\
\text { Spending } \\
\text { (LIML) }\end{array}$ & $\begin{array}{c}\text { Talking } \\
\text { w/ People } \\
\text { (1st stage) }\end{array}$ & $\begin{array}{c}\text { Education } \\
\text { Spending } \\
\text { (LIML) }\end{array}$ \\
\hline Talking with People & & $\begin{array}{l}11.827^{* * *} \\
(3.076)\end{array}$ & & $\begin{array}{l}15.020^{* * *} \\
(4.362)\end{array}$ & & $\begin{array}{l}14.756^{* * *} \\
(4.647)\end{array}$ \\
\hline Pronoun Drop & $\begin{array}{c}-.132^{* * *} \\
(.027)\end{array}$ & & $\begin{array}{c}-.108^{* * *} \\
(.035)\end{array}$ & & $\begin{array}{l}-.106^{* *} \\
(.044)\end{array}$ & \\
\hline Government Spending & & & & & $\begin{array}{l}.000 \\
(.002)\end{array}$ & $\begin{array}{l}.004 \\
(.025)\end{array}$ \\
\hline Population (log) & & & $\begin{array}{c}.004 \\
(.012)\end{array}$ & $\begin{array}{l}-.085 \\
(.140)\end{array}$ & $\begin{array}{l}.004 \\
(.012)\end{array}$ & $\begin{array}{l}-.082 \\
(.146)\end{array}$ \\
\hline No. of Ethnic Groups (log) & & & $\begin{array}{l}0.054 \\
(.039)\end{array}$ & $\begin{array}{c}-1.082 \\
(0.700)\end{array}$ & $\begin{array}{l}0.056 \\
(.039)\end{array}$ & $\begin{array}{c}-1.052 \\
(0.713)\end{array}$ \\
\hline Inverse Distance to Coast & & & $\begin{array}{l}3.875 \\
(2.794)\end{array}$ & $\begin{array}{c}-61.706 \\
(38.802)\end{array}$ & $\begin{array}{c}3.870 \\
(2.829)\end{array}$ & $\begin{array}{c}-60.765 \\
(38.759)\end{array}$ \\
\hline Temperature & & & $\begin{array}{l}-.002 \\
(.002)\end{array}$ & $\begin{array}{c}.027 \\
(.026)\end{array}$ & $\begin{array}{l}-.002 \\
(.002)\end{array}$ & $\begin{array}{l}.028 \\
(.026)\end{array}$ \\
\hline$F$ stat. of excl. instruments & 13.97 & & 9.33 & & 6.45 & \\
\hline Observations & 39 & 39 & 39 & 39 & 39 & 39 \\
\hline Clusters (Languages) & 28 & 28 & 28 & 28 & 28 & 28 \\
\hline
\end{tabular}

Notes: $* \mathrm{p} \leq 0.1 ;{ }^{* *} \mathrm{p} \leq 0.05 ;{ }^{* * *} \mathrm{p} \leq 0.01$. Standard errors are corrected for White heteroskedasticity and clustered by language. Education Spending is government expenditure on education as a percentage of GDP, average 2000-2010, from the World Development Indicators. Trust is the share of World Values Survey respondents (1981-2014) who agree with the statement: "Most people can be trusted." Talking with People is the share of WVS respondents who report that one of the "sources to learn what is going on in their country and the world" they used in the previous week was "talking with friends or colleagues." Pronoun Drop is the population share of languages that allow the speaker to omit the subject personal pronoun in a sentence, from Tabellini (2008). Government Spending is total government expense as a percentage of GDP, average 2000-2010, from the WDI. Population (log) is the logarithm of the average number of residents, 2000-2010, from the WDI. Number of Ethnic Groups (log) is from Alesina et al. (2003). Inverse Distance to Coast is the inverse of the mean distance in $\mathrm{km}$ from the nearest ice-free coastline, from Gallup, Sachs and Mellinger (1999). Temperature is the annual mean temperature in degrees Celsius, 1961-1999, from the World Bank Climate Change Knowledge Portal. 


\section{A Appendix [for Online Publication]}

\section{A.1 Definitions of the Equilibrium and of the Social Optimum}

Let the random variable $\chi\left(s_{t}, \tau_{t}, k_{t+1}, g_{t}, h_{t+1}\right)$ be an indicator for the event of re-election described by the condition:

$$
\Psi_{t} \leq \theta(p, q) \Delta_{1}\left(s_{t}, \tau_{t}, k_{t+1}, g_{t}, h_{t+1}\right)+[1-\theta(p, q)] \Delta_{0}\left(s_{t}, \tau_{t}, k_{t+1}, g_{t}\right)
$$

The dynamic equilibrium has the following definition.

Definition A1 A Markov-perfect dynamic equilibrium consists of a welfare function $V\left(s_{t}\right)$, an additional value $Z\left(s_{t}\right)$ of holding political office, a tax-setting rule $T\left(s_{t}\right)$, a private investment rule $K\left(s_{t}, \tau_{t}\right)$, and a public investment rule $H\left(s_{t}, \tau_{t}\right)$ such that:

1. The social welfare function satisfies the recursive definition:

$$
\begin{aligned}
V\left(s_{t}\right)= & (1-\gamma) \log \left\{\left[1-(1-\alpha) T\left(s_{t}\right)\right] y\left(k_{t}, h_{t}\right)-K\left(s_{t}, T\left(s_{t}\right)\right)\right\} \\
& +\gamma\left\{\log \left[(1-\alpha) T\left(s_{t}\right) y\left(k_{t}, h_{t}\right)-H\left(s_{t}, T\left(s_{t}\right)\right)\right]+\varepsilon_{t-1}^{g}+\mathbb{E}_{t} \varepsilon_{t}^{g}\right\} \\
& +\beta \mathbb{E}_{t}\left[\chi\left(s_{t}, \varepsilon_{t}^{g}, \varepsilon_{t}^{h}\right) V\left(K\left(s_{t}, T\left(s_{t}\right)\right), e^{\varepsilon_{t-1}^{h}+\varepsilon_{t}^{h}} H\left(s_{t}, T\left(s_{t}\right)\right), \varepsilon_{t}^{g}, \varepsilon_{t}^{h}\right)\right] \\
+ & \beta \mathbb{E}_{t}\left\{\left[1-\chi\left(s_{t}, \varepsilon_{t}^{g}, \varepsilon_{t}^{h}\right)\right] V\left(K\left(s_{t}, T\left(s_{t}\right)\right), e^{\varepsilon_{t-1}^{h}+\varepsilon_{t}^{h}} H\left(s_{t}, T\left(s_{t}\right)\right), \omega_{t}^{g}, \omega_{t}^{h}\right)\right\},
\end{aligned}
$$

where for ease of notation:

$$
\chi\left(s_{t}, \varepsilon_{t}^{g}, \varepsilon_{t}^{h}\right) \equiv \chi\left(\begin{array}{r}
s_{t}, T\left(s_{t}\right), K\left(s_{t}, T\left(s_{t}\right)\right), \\
e^{\varepsilon_{t-1}^{g}+\varepsilon_{t}^{g}}\left[(1-\alpha) T\left(s_{t}\right) y\left(k_{t}, h_{t}\right)-H\left(s_{t}, T\left(s_{t}\right)\right)\right], \\
e^{\varepsilon_{t-1}^{h}+\varepsilon_{t}^{h}} H\left(s_{t}, T\left(s_{t}\right)\right)
\end{array}\right) .
$$

2. The additional value of political incumbency satisfies the recursive definition:

$$
Z\left(s_{t}\right)=z+\beta \mathbb{E}_{t}\left[\chi\left(s_{t}, \varepsilon_{t}^{g}, \varepsilon_{t}^{h}\right) Z\left(K\left(s_{t}, T\left(s_{t}\right)\right), e^{\varepsilon_{t-1}^{h}+\varepsilon_{t}^{h}} H\left(s_{t}, T\left(s_{t}\right)\right), \varepsilon_{t}^{g}, \varepsilon_{t}^{h}\right)\right],
$$

with the same simplified notation for $\chi\left(s_{t}, \varepsilon_{t}^{g}, \varepsilon_{t}^{h}\right)$.

3. Labor-income taxes are chosen by office-seeking politicians:

$$
\begin{aligned}
& T\left(s_{t}\right)= \\
& \arg \max _{T}\left\{\begin{array}{c}
(1-\gamma) \log \left\{[1-(1-\alpha) T] y\left(k_{t}, h_{t}\right)-K\left(s_{t}, T\right)\right\} \\
+\gamma \log \left[(1-\alpha) T y\left(k_{t}, h_{t}\right)-H\left(s_{t}, T\right)\right] \\
+\beta \mathbb{E}_{t}\left\{\begin{array}{c}
\left.\chi\left(s_{t}, T, \varepsilon_{t}^{g}, \varepsilon_{t}^{h}\right)\left[\begin{array}{c}
V\left(K\left(s_{t}, T\right), e^{\varepsilon_{t-1}^{h}+\varepsilon_{t}^{h}} H\left(s_{t}, T\right), \varepsilon_{t}^{g}, \varepsilon_{t}^{h}\right) \\
+Z\left(K\left(s_{t}, T\right), e^{\varepsilon_{t-1}^{h}+\varepsilon_{t}^{h}} H\left(s_{t}, T\right), \varepsilon_{t}^{g}, \varepsilon_{t}^{h}\right)
\end{array}\right]\right\} \\
+\beta \mathbb{E}_{t}\left\{\left[1-\chi\left(s_{t}, T, \varepsilon_{t}^{g}, \varepsilon_{t}^{h}\right)\right] V\left(K\left(s_{t}, T\right), e^{\varepsilon_{t-1}^{h}+\varepsilon_{t}^{h}} H\left(s_{t}, T\right), \omega_{t}^{g}, \omega_{t}^{h}\right)\right.
\end{array}\right\},
\end{array}\right.
\end{aligned}
$$


where for ease of notation:

$$
\begin{aligned}
& \chi\left(s_{t}, T, \varepsilon_{t}^{g}, \varepsilon_{t}^{h}\right) \equiv \\
& \quad \chi\left(s_{t}, T, K\left(s_{t}, T\right), e^{\varepsilon_{t-1}^{g}+\varepsilon_{t}^{g}}\left[(1-\alpha) T y\left(k_{t}, h_{t}\right)-H\left(s_{t}, T\right)\right], e^{\varepsilon_{t-1}^{h}+\varepsilon_{t}^{h}} H\left(s_{t}, T\right)\right) .
\end{aligned}
$$

4. Expenditure on public investment is chosen by office-seeking politicians:

$$
\begin{aligned}
& H\left(s_{t}, \tau_{t}\right)= \\
& \arg \max _{H}\left\{\begin{array}{c}
\gamma \log \left[(1-\alpha) \tau_{t} y\left(k_{t}, h_{t}\right)-H\right] \\
+\beta \mathbb{E}_{t}\left\{\chi\left(s_{t}, \tau_{t}, H, \varepsilon_{t}^{g}, \varepsilon_{t}^{h}\right)\left[\begin{array}{c}
V\left(K\left(s_{t}, \tau_{t}\right), e^{\varepsilon_{t-1}^{h}+\varepsilon_{t}^{h}} H, \varepsilon_{t}^{g}, \varepsilon_{t}^{h}\right) \\
+Z\left(K\left(s_{t}, \tau_{t}\right), e^{\varepsilon_{t-1}^{h}+\varepsilon_{t}^{h}} H, \varepsilon_{t}^{g}, \varepsilon_{t}^{h}\right)
\end{array}\right]\right\} \\
+\beta \mathbb{E}_{t}\left\{\left[1-\chi\left(s_{t}, \tau_{t}, H, \varepsilon_{t}^{g}, \varepsilon_{t}^{h}\right)\right] V\left(K\left(s_{t}, \tau_{t}\right), e^{\varepsilon_{t-1}^{h}+\varepsilon_{t}^{h}} H, \omega_{t}^{g}, \omega_{t}^{h}\right)\right\}
\end{array}\right\} .
\end{aligned}
$$

where for ease of notation:

$$
\begin{aligned}
\chi\left(s_{t}, \tau_{t}, H, \varepsilon_{t}^{g}, \varepsilon_{t}^{h}\right) \equiv \\
\\
\chi\left(s_{t}, T\left(s_{t}\right), K\left(s_{t}, T\left(s_{t}\right)\right), e^{\varepsilon_{t-1}^{g}+\varepsilon_{t}^{g}}\left[(1-\alpha) \tau_{t} y\left(k_{t}, h_{t}\right)-H\right], e^{\varepsilon_{t-1}^{h}+\varepsilon_{t}^{h}} H\right) .
\end{aligned}
$$

5. Private investment is chosen by utility-maximizing households:

$$
\begin{aligned}
K\left(s_{t}, \tau_{t}\right)= & \arg \max _{K}\left\{\begin{array}{r}
(1-\gamma) \log \left\{\left[1-(1-\alpha) \tau_{t}\right] y\left(k_{t}, h_{t}\right)-K\right\} \\
\quad+\beta \mathbb{E}_{t}\left[\chi\left(s_{t}, \tau_{t}, K, \varepsilon_{t}^{g}, \varepsilon_{t}^{h}\right) V\left(K, e^{\varepsilon_{t-1}^{h}+\varepsilon_{t}^{h}} H\left(s_{t}, \tau_{t}\right), \varepsilon_{t}^{g}, \varepsilon_{t}^{h}\right)\right] \\
+\beta \mathbb{E}_{t}\left\{\left[1-\chi\left(s_{t}, \tau_{t}, K, \varepsilon_{t}^{g}, \varepsilon_{t}^{h}\right)\right] V\left(K, e^{\varepsilon_{t-1}^{h}+\varepsilon_{t}^{h}} H\left(s_{t}, \tau_{t}\right), \omega_{t}^{g}, \omega_{t}^{h}\right)\right\}
\end{array}\right\} .
\end{aligned}
$$

where for ease of notation:

$$
\begin{aligned}
\chi\left(s_{t}, \tau_{t}, K,\right. & \left.\varepsilon_{t}^{g}, \varepsilon_{t}^{h}\right) \equiv \\
& \chi\left(s_{t}, \tau_{t}, K, e^{\varepsilon_{t-1}^{g}+\varepsilon_{t}^{g}}\left[(1-\alpha) \tau_{t} y\left(k_{t}, h_{t}\right)-H\left(s_{t}, \tau_{t}\right)\right], e^{\varepsilon_{t-1}^{h}+\varepsilon_{t}^{h}} H\left(s_{t}, \tau_{t}\right)\right) .
\end{aligned}
$$

Let the binary function $\chi^{*}\left(s_{t}, \varepsilon_{t}^{g}, \varepsilon_{t}^{h}\right)$ equal one if the incumbent is retained and zero if he is replaced by a new random draw from the ability pool. The social optimum has the following characterization.

Definition A2 The solution to the planner's problem consists of a welfare function $V^{*}\left(s_{t}\right)$, a private investment rule $K^{*}\left(s_{t}\right)$, public spending rules $G^{*}\left(s_{t}\right)$ and $H^{*}\left(s_{t}\right)$, and a re-election rule $\chi^{*}\left(s_{t}, \varepsilon_{t}^{g}, \varepsilon_{t}^{h}\right)$ such that: 
1. The social welfare function satisfies the recursive definition:

$$
\begin{aligned}
V^{*}\left(s_{t}\right)=(1-\gamma) & \log \left[y\left(k_{t}, h_{t}\right)-K^{*}\left(s_{t}\right)-G^{*}\left(s_{t}\right)-H^{*}\left(s_{t}\right)\right] \\
& +\gamma\left[\log G^{*}\left(s_{t}\right)+\varepsilon_{t-1}^{g}+\mathbb{E}_{t} \varepsilon_{t}^{g}\right] \\
+ & \mathbb{E}_{t}\left[\chi^{*}\left(s_{t}, \varepsilon_{t}^{g}, \varepsilon_{t}^{h}\right) V\left(K^{*}\left(s_{t}\right), e^{\varepsilon_{t-1}^{h}+\varepsilon_{t}^{h}} H^{*}\left(s_{t}\right), \varepsilon_{t}^{g}, \varepsilon_{t}^{h}\right)\right] \\
& +\beta \mathbb{E}_{t}\left\{\left[1-\chi^{*}\left(s_{t}, \varepsilon_{t}^{g}, \varepsilon_{t}^{h}\right)\right] V\left(K^{*}\left(s_{t}\right), e^{\varepsilon_{t-1}^{h}+\varepsilon_{t}^{h}} H^{*}\left(s_{t}\right), \omega_{t}^{g}, \omega_{t}^{h}\right)\right\} .
\end{aligned}
$$

2. The allocation of output $K^{*}\left(s_{t}\right), G^{*}\left(s_{t}\right), H^{*}\left(s_{t}\right)$ solves:

$$
\max _{K, G, H}\left\{\begin{array}{c}
(1-\gamma) \log \left[y\left(k_{t}, h_{t}\right)-K-G-H\right]+\gamma \log G \\
+\beta \mathbb{E}_{t}\left[\chi^{*}\left(s_{t}, \varepsilon_{t}^{g}, \varepsilon_{t}^{h}\right) V\left(K, e^{\varepsilon_{t-1}^{h}+\varepsilon_{t}^{h}} H, \varepsilon_{t}^{g}, \varepsilon_{t}^{h}\right)\right] \\
+\beta \mathbb{E}_{t}\left\{\left[1-\chi^{*}\left(s_{t}, \varepsilon_{t}^{g}, \varepsilon_{t}^{h}\right)\right] V\left(K, e^{\varepsilon_{t-1}^{h}+\varepsilon_{t}^{h}} H, \omega_{t}^{g}, \omega_{t}^{h}\right)\right\}
\end{array}\right\} .
$$

3. The re-election rule is $\chi^{*}\left(s_{t}, \varepsilon_{t}^{g}, \varepsilon_{t}^{h}\right)=1$ if and only if:

$$
V\left(K^{*}\left(s_{t}\right), e^{\varepsilon_{t-1}^{h}+\varepsilon_{t}^{h}} H^{*}\left(s_{t}\right), \varepsilon_{t}^{g}, \varepsilon_{t}^{h}\right) \geq \mathbb{E}_{t} V\left(K^{*}\left(s_{t}\right), e^{\varepsilon_{t-1}^{h}+\varepsilon_{t}^{h}} H^{*}\left(s_{t}\right), \omega_{t}^{g}, \omega_{t}^{h}\right) .
$$

\section{A.2 Proof of Proposition 1 and Corollary 1}

To solve the planner's problem, we make an educated guess for the form of the social welfare function:

$$
V^{*}\left(s_{t}\right)=v_{0}+v_{k} \log k_{t}+v_{h} \log h_{t}+v_{\varepsilon}^{g} \varepsilon_{t-1}^{g}+v_{\varepsilon}^{h} \varepsilon_{t-1}^{h} .
$$

Then the allocation of output solves:

$$
\max _{K, G, H}\left\{(1-\gamma) \log \left[y\left(k_{t}, h_{t}\right)-K-G-H\right]+\gamma \log G+\beta\left(\left[v_{k} \log K+v_{h} \log H\right]\right)\right\},
$$

which implies constant output shares:

$$
\begin{aligned}
\frac{K^{*}\left(s_{t}\right)}{y\left(k_{t}, h_{t}\right)} & =\frac{\beta v_{k}}{1+\beta\left(v_{k}+v_{h}\right)}, \\
\frac{G^{*}\left(s_{t}\right)}{y\left(k_{t}, h_{t}\right)} & =\frac{\gamma}{1+\beta\left(v_{k}+v_{h}\right)},
\end{aligned}
$$

and

$$
\frac{H^{*}\left(s_{t}\right)}{y\left(k_{t}, h_{t}\right)}=\frac{\beta v_{h}}{1+\beta\left(v_{k}+v_{h}\right)} ;
$$

the re-election rule is $\chi^{*}\left(s_{t}, \varepsilon_{t}^{g}, \varepsilon_{t}^{h}\right)=1$ if and only if:

$$
v_{\varepsilon}^{g} \varepsilon_{t}^{g}+v_{\varepsilon}^{h} \varepsilon_{t}^{h} \geq 0
$$


and social welfare is:

$$
\begin{aligned}
V^{*}\left(s_{t}\right)=(1-\gamma) \log [ & \left.\frac{1-\gamma}{1+\beta\left(v_{k}+v_{h}\right)} y\left(k_{t}, h_{t}\right)\right] \\
& +\gamma\left\{\log \left[\frac{\gamma}{1+\beta\left(v_{k}+v_{h}\right)} y\left(k_{t}, h_{t}\right)\right]+\varepsilon_{t-1}^{g}\right\} \\
& +\beta v_{k} \log \left[\frac{\beta v_{k}}{1+\beta\left(v_{k}+v_{h}\right)} y\left(k_{t}, h_{t}\right)\right] \\
+ & \beta v_{h}\left\{\log \left[\frac{\beta v_{h}}{1+\beta\left(v_{k}+v_{h}\right)} y\left(k_{t}, h_{t}\right)\right]+\varepsilon_{t-1}^{h}\right\} \\
& +\beta \mathbb{E}\left[v_{\varepsilon}^{g} \varepsilon_{t}^{g}+v_{\varepsilon}^{h} \varepsilon_{t}^{h} \geq 0\right],
\end{aligned}
$$

where $\mathbb{E}[X \geq 0]$ denotes the partial expectation $\int_{0}^{\infty} X d F(X)$.

Thus the guess is correct for:

$$
v_{k}=\alpha\left[1+\beta\left(v_{k}+v_{h}\right)\right], v_{h}=(1-\alpha)\left[1+\beta\left(v_{k}+v_{h}\right)\right], v_{\varepsilon}^{g}=\gamma, v_{\varepsilon}^{h}=\beta v_{h},
$$

and

$$
\begin{aligned}
v_{0}=(1 & -\gamma) \log \frac{1-\gamma}{1+\beta\left(v_{k}+v_{h}\right)}+\gamma \log \frac{\gamma}{1+\beta\left(v_{k}+v_{h}\right)}+\beta v_{k} \log \frac{\beta v_{k}}{1+\beta\left(v_{k}+v_{h}\right)} \\
& +\beta v_{h} \log \frac{\beta v_{h}}{1+\beta\left(v_{k}+v_{h}\right)}+\left[1+\beta\left(v_{k}+v_{h}\right)\right] \log A+\beta \mathbb{E}\left[v_{\varepsilon}^{g} \varepsilon_{t}^{g}+v_{\varepsilon}^{h} \varepsilon_{t}^{h} \geq 0\right] .
\end{aligned}
$$

Solving for the coefficients and plugging them into the expressions above yields the exact solution to the planner's problem.

The growth rate of output is:

$$
\log y_{t+1}-\log y_{t}=(1-\alpha) \log (1-\alpha)+\alpha \log \alpha+\log \beta+\log A+(1-\alpha) \eta_{t}^{*}
$$

where the optimal competence of the ruling politician is:

$$
\eta_{t}^{*}=\chi_{t-1}^{*}\left(\varepsilon_{t-1}^{h}+\varepsilon_{t}^{h}\right)+\left(1-\chi_{t-1}^{*}\right)\left(\omega_{t-1}^{h}+\omega_{t}^{h}\right),
$$

such that:

$$
\begin{aligned}
\mathbb{E} \eta_{t}^{*}=\mathbb{E}\left(\chi_{t-1}^{*} \varepsilon_{t-1}^{h}\right)=\int_{-\infty}^{\infty}\left[1-F_{g}\left(-\frac{\beta(1-\alpha)}{(1-\beta) \gamma} \varepsilon\right)\right] \varepsilon d F_{h}(\varepsilon)= \\
=\int_{-\infty}^{\infty}\left[F_{g}(0)-F_{g}\left(-\frac{\beta(1-\alpha)}{(1-\beta) \gamma} \varepsilon\right)\right] \varepsilon d F_{h}(\varepsilon)+\left[1-F_{g}(0)\right] \int_{-\infty}^{\infty} \varepsilon d F_{h}(\varepsilon) \\
=\int_{-\infty}^{\infty}\left|\left[F_{g}(0)-F_{g}\left(-\frac{\beta(1-\alpha)}{(1-\beta) \gamma} \varepsilon\right)\right] \varepsilon\right| d F_{h}(\varepsilon) \geq 0 .
\end{aligned}
$$




\section{A.3 Proof of Proposition 2}

To solve for the equilibrium, we make educated guesses for the functional forms of social welfare:

$$
V\left(s_{t}\right)=v_{0}+v_{k} \log k_{t}+v_{h} \log h_{t}+v_{\varepsilon}^{g} \varepsilon_{t-1}^{g}+v_{\varepsilon}^{h} \varepsilon_{t-1}^{h},
$$

and of the value of incumbency:

$$
Z\left(s_{t}\right)=Z \text {. }
$$

The guess (A14) for the welfare function suffices to establish that private savings are:

$$
\begin{aligned}
K\left(s_{t}, \tau_{t}\right)=\arg \max _{K}\left\{(1-\gamma) \log \left\{\left[1-(1-\alpha) \tau_{t}\right] y\left(k_{t}, h_{t}\right)-K\right\}+\beta v_{k} \log K\right\} \\
=\frac{\beta v_{k}}{1-\gamma+\beta v_{k}}\left[1-(1-\alpha) \tau_{t}\right] y\left(k_{t}, h_{t}\right) .
\end{aligned}
$$

Recalling that $\mathbb{E} \omega_{t}^{g}=\mathbb{E}_{\omega} \omega_{t}^{h}=\mathbb{E} \varepsilon_{t}^{h}=0,(\mathrm{~A} 14)$ also implies that voters' policy preferences are:

$$
\Delta_{1}\left(s_{t}, \tau_{t}, k_{t+1}, g_{t}, h_{t+1}\right)=v_{\varepsilon}^{g} \varepsilon^{g}\left(s_{t}, \tau_{t}, g_{t}\right)+v_{\varepsilon}^{h} \varepsilon^{h}\left(s_{t}, \tau_{t}, h_{t+1}\right)
$$

for the share $\theta(p, q)$ of citizens who have observed $h_{t+1}$, and:

$$
\Delta_{0}\left(s_{t}, \tau_{t}, k_{t+1}, g_{t}\right)=v_{\varepsilon}^{g} \varepsilon^{g}\left(s_{t}, \tau_{t}, g_{t}\right)
$$

the remainder $1-\theta(p, q)$ of voters who have not observed $h_{t+1}$. Then $\chi\left(s_{t}\right)$ as defined in Definition (1) is an indicator for:

$$
\begin{array}{r}
\Psi_{t} \leq v_{\varepsilon}^{g} \varepsilon^{g}\left(s_{t}, T\left(s_{t}\right),\left[(1-\alpha) T\left(s_{t}\right) y\left(k_{t}, h_{t}\right)-H\left(s_{t}, T\left(s_{t}\right)\right)\right] \exp \left(\varepsilon_{t-1}^{g}+\varepsilon_{t}^{g}\right)\right) \\
+\theta(p, q) v_{\varepsilon}^{h} \varepsilon^{h}\left(s_{t}, T\left(s_{t}\right), H\left(s_{t}, T\left(s_{t}\right)\right) \exp \left(\varepsilon_{t-1}^{h}+\varepsilon_{t}^{h}\right)\right) .
\end{array}
$$

In equilibrium, regardless of the form of the welfare function, voters' inference is correct. Equations (15) and (16) imply that:

$$
\varepsilon^{g}\left(s_{t}, T\left(s_{t}\right),\left[(1-\alpha) T\left(s_{t}\right) y\left(k_{t}, h_{t}\right)-H\left(s_{t}, T\left(s_{t}\right)\right)\right] \exp \left(\varepsilon_{t-1}^{g}+\varepsilon_{t}^{g}\right)\right)=\varepsilon_{t}^{g}
$$

and

$$
\varepsilon^{h}\left(s_{t}, T\left(s_{t}\right), H\left(s_{t}, T\left(s_{t}\right)\right) \exp \left(\varepsilon_{t-1}^{h}+\varepsilon_{t}^{h}\right)\right)=\varepsilon_{t}^{h} .
$$

As a consequence, $\chi\left(s_{t}\right)$ is an indicator for:

$$
\Psi_{t} \leq v_{\varepsilon}^{g} \varepsilon_{t}^{g}+\theta(p, q) v_{\varepsilon}^{h} \varepsilon_{t}^{h}
$$

whose distribution is independent of $s_{t}$.

We assume that the support of all shocks is such that neither the aggregate outcome of the election nor any single voter's ballot is perfectly predictable on the basis of $g_{t}$ and $h_{t+1}$ alone. Formally:

$$
\Psi_{t} \sim U\left[-\frac{1}{2 \phi}, \frac{1}{2 \phi}\right] \text { and } \psi_{t}^{i} \stackrel{i i d}{\sim} U[-\bar{\psi}, \bar{\psi}]
$$


such that:

$$
\begin{aligned}
\max \left\{-\frac{1}{2 \phi}, \frac{1}{2 \phi}-\bar{\psi}\right\} \leq-\left[\gamma \hat{\varepsilon}_{g}+\frac{(1-\alpha) \beta}{1-\beta} \hat{\varepsilon}_{h}\right]< \\
\gamma \hat{\varepsilon}_{g}+\frac{(1-\alpha) \beta}{1-\beta} \hat{\varepsilon}_{h} \leq \min \left\{\frac{1}{2 \phi}, \bar{\psi}-\frac{1}{2 \phi}\right\} .
\end{aligned}
$$

Then the uniform distribution of $\Psi_{t}$ implies that:

$$
\mathbb{E} \chi\left(s_{t}\right)=\frac{1}{2} .
$$

The guess (A15) for the value of holding political office is then correct for a constant:

$$
Z=\frac{2 z}{2-\beta}
$$

conditional on the guess (A14) for the welfare function being correct.

Given (A14) and the ensuing value of office $Z$, expenditure on public investment is then:

$$
H\left(s_{t}, \tau_{t}\right)=\arg \max _{H}\left\{\begin{array}{r}
\gamma \log \left[(1-\alpha) \tau_{t} y\left(k_{t}, h_{t}\right)-H\right]+\beta v_{h} \log H \\
+\beta \mathbb{E}\left[\left(v_{\varepsilon}^{g} \varepsilon_{t}^{g}+v_{\varepsilon}^{h} \varepsilon_{t}^{h}+Z\right) \chi\left(s_{t}, \tau_{t}, H\right)\right]
\end{array}\right\},
$$

recalling that $\chi\left(s_{t}, \tau_{t}, H\right)$ is independent of the unobservable challenger shocks $\omega_{t}^{g}$ and $\omega_{t}^{h}$. Moreover, the simplification for $\Delta_{1}$ and $\Delta_{0}$ found above and the inferences (15) and (16) imply that $\chi\left(s_{t}, \tau_{t}, H\right)$ is an indicator for:

$$
\begin{array}{r}
\Psi_{t} \leq v_{\varepsilon}^{g}\left\{\varepsilon_{t}^{g}+\log \left[(1-\alpha) \tau_{t} y\left(k_{t}, h_{t}\right)-H\right]-\log \left[(1-\alpha) \tau_{t} y\left(k_{t}, h_{t}\right)-H\left(s_{t}, \tau_{t}\right)\right]\right\} \\
+\theta(p, q) v_{\varepsilon}^{h}\left[\varepsilon_{t}^{h}+\log H-\log H\left(s_{t}, \tau_{t}\right)\right],
\end{array}
$$

such that:

$$
\begin{aligned}
& \mathbb{E} \chi\left(s_{t}, \tau_{t}, H\right)=\frac{1}{2} \\
&+\phi v_{\varepsilon}^{g}\left\{\log \left[(1-\alpha) \tau_{t} y\left(k_{t}, h_{t}\right)-H\right]-\right.\left.\log \left[(1-\alpha) \tau_{t} y\left(k_{t}, h_{t}\right)-H\left(s_{t}, \tau_{t}\right)\right]\right\} \\
&+\phi \theta(p, q) v_{\varepsilon}^{h}\left[\log H-\log H\left(s_{t}, \tau_{t}\right)\right],
\end{aligned}
$$

while

$$
\mathbb{E}\left[\varepsilon_{t}^{g} \chi\left(s_{t}, \tau_{t}, H\right)\right]=\phi v_{\varepsilon}^{g} \sigma_{g}^{2} \text { and } \mathbb{E}\left[\varepsilon_{t}^{h} \chi\left(s_{t}, \tau_{t}, H\right)\right]=\phi \theta(p, q) v_{\varepsilon}^{h} \sigma_{h}^{2} .
$$

Plugging these in:

$$
\begin{aligned}
& H\left(s_{t}, \tau_{t}\right)= \\
& \arg \max _{H}\left\{\left(\gamma+\beta Z \phi v_{\varepsilon}^{g}\right) \log \left[(1-\alpha) \tau_{t} y\left(k_{t}, h_{t}\right)-H\right]+\beta\left[v_{h}+Z \phi \theta(p, q) v_{\varepsilon}^{h}\right] \log H\right\} \\
& =\frac{\beta\left[v_{h}+Z \phi \theta(p, q) v_{\varepsilon}^{h}\right]}{\gamma+\beta\left\{v_{h}+Z \phi\left[v_{\varepsilon}^{g}+\theta(p, q) v_{\varepsilon}^{h}\right]\right\}}(1-\alpha) \tau_{t} y\left(k_{t}, h_{t}\right) .
\end{aligned}
$$


Given the guess (A14) and the ensuing value of office $Z$, labor-income taxes are:

$$
T\left(s_{t}\right)=\arg \max _{T}\left\{\begin{array}{l}
(1-\gamma) \log \left\{[1-(1-\alpha) T] y\left(k_{t}, h_{t}\right)-K\left(s_{t}, T\right)\right\} \\
+\gamma \log \left[(1-\alpha) T y\left(k_{t}, h_{t}\right)-H\left(s_{t}, T\right)\right] \\
+\beta\left[v_{k} \log K\left(s_{t}, T\right)+v_{h} \log H\left(s_{t}, T\right)\right] \\
+\beta \mathbb{E}\left[\left(v_{\varepsilon}^{g} \varepsilon_{t}^{g}+v_{\varepsilon}^{h} \varepsilon_{t}^{h}+Z\right) \chi\left(s_{t}, T\right)\right]
\end{array}\right\},
$$

where $\chi\left(s_{t}, T\right)$ is an indicator for:

$$
\Psi_{t} \leq v_{\varepsilon}^{g} \varepsilon_{t}^{g}+\theta(p, q) v_{\varepsilon}^{h} \varepsilon_{t}^{h}
$$

such that:

$$
\mathbb{E} \chi\left(s_{t}, T\right)=\frac{1}{2}, \mathbb{E}\left[\varepsilon_{t}^{g} \chi\left(s_{t}, T\right)\right]=\phi v_{\varepsilon}^{g} \sigma_{g}^{2} \text { and } \mathbb{E}\left[\varepsilon_{t}^{h} \chi\left(s_{t}, T\right)\right]=\phi \theta(p, q) v_{\varepsilon}^{h} \sigma_{h}^{2} .
$$

Hence, considering the solutions for $K\left(s_{t}, \tau_{t}\right)$, and $H\left(s_{t}, \tau_{t}\right)$, taxes are:

$$
\begin{aligned}
T\left(s_{t}\right)=\arg \max _{T}\left\{\left(1-\gamma+\beta v_{k}\right) \log [1-(1-\alpha) T]+\left(\gamma+\beta v_{h}\right) \log T\right\} & \\
& =\frac{1}{1-\alpha} \frac{\gamma+\beta v_{h}}{1+\beta\left(v_{k}+v_{h}\right)} .
\end{aligned}
$$

Finally, using the guess (A14) on the right-hand side of the recursive definition of the social welfare function itself:

$$
\begin{aligned}
V\left(s_{t}\right)=(1-\gamma) & \log \left\{\left[1-(1-\alpha) T\left(s_{t}\right)\right] y\left(k_{t}, h_{t}\right)-K\left(s_{t}, T\left(s_{t}\right)\right)\right\} \\
+ & \gamma\left\{\log \left[(1-\alpha) T\left(s_{t}\right) y\left(k_{t}, h_{t}\right)-H\left(s_{t}, T\left(s_{t}\right)\right)\right]+\varepsilon_{t-1}^{g}\right\} \\
+ & \beta\left\{v_{k} \log K\left(s_{t}, T\left(s_{t}\right)\right)+v_{h}\left[\log H\left(s_{t}, T\left(s_{t}\right)\right)+\varepsilon_{t-1}^{h}\right]\right\} \\
& +\beta \mathbb{E}\left[\left(v_{\varepsilon}^{g} \varepsilon_{t}^{g}+v_{\varepsilon}^{h} \varepsilon_{t}^{h}\right) \chi\left(s_{t}\right)\right]+\beta \mathbb{E}\left\{\left(v_{\varepsilon}^{g} \omega_{t}^{g}+v_{\varepsilon}^{h} \omega_{t}^{h}\right)\left[1-\chi\left(s_{t}\right)\right]\right\} .
\end{aligned}
$$

The distribution of $\chi\left(s_{t}\right)$ and the solutions for $K\left(s_{t}, \tau_{t}\right), H\left(s_{t}, \tau_{t}\right)$, and $T\left(s_{t}\right)$ then imply that:

$$
\begin{array}{r}
V\left(s_{t}\right)=(1-\gamma) \log \left[\frac{1-\gamma}{1+\beta\left(v_{k}+v_{h}\right)} y\left(k_{t}, h_{t}\right)\right] \\
+\gamma\left(\log \left\{\frac{\gamma+\beta Z \phi v_{\varepsilon}^{g}}{1+\beta\left(v_{k}+v_{h}\right)} \frac{\gamma+\beta v_{h}}{\gamma+\beta v_{h}+\beta Z \phi\left[v_{\varepsilon}^{g}+\theta(p, q) v_{\varepsilon}^{h}\right]} y\left(k_{t}, h_{t}\right)\right\}+\varepsilon_{t-1}^{g}\right) \\
+\beta v_{k} \log \left[\frac{\beta v_{k}}{1+\beta\left(v_{k}+v_{h}\right)} y\left(k_{t}, h_{t}\right)\right] \\
+\beta v_{h}\left(\log \left\{\beta \frac{v_{h}+Z \phi \theta(p, q) v_{\varepsilon}^{h}}{1+\beta\left(v_{k}+v_{h}\right)} \frac{\gamma+\beta v_{h}}{\gamma+\beta v_{h}+\beta Z \phi\left[v_{\varepsilon}^{g}+\theta(p, q) v_{\varepsilon}^{h}\right]} y\left(k_{t}, h_{t}\right)\right\}+\varepsilon_{t-1}^{h}\right) \\
+\beta \phi\left[\left(v_{\varepsilon}^{g} \sigma_{g}\right)^{2}+\theta(p, q)\left(v_{\varepsilon}^{h} \sigma_{h}\right)^{2}\right] .
\end{array}
$$

Recalling the Cobb-Douglas production function (11), our educated guess (A14) is correct 
for:

$$
v_{k}=\alpha\left[1+\beta\left(v_{k}+v_{h}\right)\right], v_{h}=(1-\alpha)\left[1+\beta\left(v_{k}+v_{h}\right)\right], v_{\varepsilon}^{g}=\gamma, v_{\varepsilon}^{h}=\beta v_{h},
$$

and

$$
\begin{aligned}
& v_{0}=(1-\gamma) \log \frac{1-\gamma}{1+\beta\left(v_{k}+v_{h}\right)}+\beta v_{k} \log \frac{\beta v_{k}}{1+\beta\left(v_{k}+v_{h}\right)} \\
&+\gamma \log \left\{\frac{\gamma+\beta Z \phi v_{\varepsilon}^{g}}{1+\beta\left(v_{k}+v_{h}\right)} \frac{\gamma+\beta v_{h}}{\gamma+\beta v_{h}+\beta \phi\left[v_{\varepsilon}^{g}+\theta(p, q) v_{\varepsilon}^{h}\right]}\right\} \\
&+\beta v_{h} \log \left\{\beta \frac{v_{h}+Z \phi \theta(p, q) v_{\varepsilon}^{h}}{1+\beta\left(v_{k}+v_{h}\right)} \frac{\gamma+\beta v_{h}}{\gamma+\beta v_{h}+\beta Z \phi\left[v_{\varepsilon}^{g}+\theta(p, q) v_{\varepsilon}^{h}\right]}\right\} \\
&+\left[1+\beta\left(v_{k}+v_{h}\right)\right] \log A+\beta \phi\left[\left(v_{\varepsilon}^{g} \sigma_{g}\right)^{2}+\theta(p, q)\left(v_{\varepsilon}^{h} \sigma_{h}\right)^{2}\right] .
\end{aligned}
$$

Solving out:

$$
v_{k}=\frac{\alpha}{1-\beta}, v_{h}=\frac{1-\alpha}{1-\beta}, v_{\varepsilon}^{g}=\gamma, v_{\varepsilon}^{h}=\frac{(1-\alpha) \beta}{1-\beta},
$$

and

$$
\begin{aligned}
(1-\beta) v_{0}=(1-\beta)(1-\gamma) \log [(1-\beta)(1-\gamma)]+\alpha \beta \log (\alpha \beta) \\
+(1-\beta) \gamma \log [(1-\beta) \gamma+\zeta]+(1-\alpha) \beta \log [(1-\alpha) \beta-\zeta] \\
+\log A+\frac{\beta}{1-\beta} \phi\left\{\left[(1-\beta) \gamma \sigma_{g}\right]^{2}+\theta(p, q)\left[(1-\alpha) \beta \sigma_{h}\right]^{2}\right\}
\end{aligned}
$$

for:

$$
\zeta \equiv \frac{(1-\alpha) \beta^{2}(1-\beta) \gamma Z \phi[1-\theta(p, q)]}{(1-\beta) \gamma(1+\beta Z \phi)+(1-\alpha) \beta[1+\beta Z \phi \theta(p, q)]}
$$

such that:

$$
\frac{\partial \zeta}{\partial q}=-\frac{(1-\alpha) \beta^{2}(1-\beta) \gamma[(1-\alpha) \beta+(1-\beta) \gamma](1+\beta Z \phi) Z \phi}{\{(1-\beta) \gamma(1+\beta Z \phi)+(1-\alpha) \beta[1+\beta Z \phi \theta(p, q)]\}^{2}} \frac{\partial \theta}{\partial q}<0 .
$$

We can collect the results above in an exact solution for all equilibrium functions. The social welfare function depends on social capital according to:

$$
\frac{\partial V}{\partial q}=-\frac{[(1-\alpha) \beta+(1-\beta) \gamma] \zeta}{(1-\beta)[(1-\alpha) \beta-\zeta][(1-\beta) \gamma+\zeta]} \frac{\partial \zeta}{\partial q}+\beta \phi\left[\frac{(1-\alpha) \beta}{1-\beta} \sigma_{h}\right]^{2} \frac{\partial \theta}{\partial q}>0
$$

\section{A.4 Proof of Proposition 3}

The electoral process implies that the competence of the ruling politician evolves according to:

$$
\hat{\eta}_{t}=\chi_{t-1}\left(\varepsilon_{t-1}+\varepsilon_{t}\right)+\left(1-\chi_{t-1}\right)\left(\omega_{t-1}+\omega_{t}\right)
$$


where $\chi_{t-1}$ is an indicator for:

$$
\Psi_{t-1} \leq \gamma \varepsilon_{t-1}^{g}+\frac{(1-\alpha) \beta}{1-\beta} \theta(p, q) \varepsilon_{t-1}^{h}
$$

The cumulative distribution function of $\hat{\eta}_{t}^{h}$ is:

$$
\begin{gathered}
\operatorname{Pr}\left(\hat{\eta}_{t}^{h} \leq \eta\right)=\operatorname{Pr}\left[\chi_{t-1}\left(\varepsilon_{t-1}^{h}+\varepsilon_{t}^{h}\right)+\left(1-\chi_{t-1}\right)\left(\omega_{t-1}^{h}+\omega_{t}^{h}\right) \leq \eta\right] \\
=\operatorname{Pr}\left(\chi_{t-1}=1 \wedge \varepsilon_{t-1}^{h}+\varepsilon_{t}^{h} \leq \eta\right)+\operatorname{Pr}\left(\chi_{t-1}=0 \wedge \omega_{t-1}^{h}+\omega_{t}^{h} \leq \eta\right) \\
=\operatorname{Pr}\left[\Psi_{t-1} \leq \gamma \varepsilon_{t-1}^{g}+\frac{(1-\alpha) \beta}{1-\beta} \theta(p, q) \varepsilon_{t-1}^{h} \wedge \varepsilon_{t-1}^{h}+\varepsilon_{t}^{h} \leq \eta\right]+\frac{1}{2} \operatorname{Pr}\left(\omega_{t-1}^{h}+\omega_{t}^{h} \leq \eta\right) \\
=\int_{-\infty}^{\infty}\left[1+\frac{(1-\alpha) \beta}{1-\beta} \theta(p, q) \phi \varepsilon\right] F_{h}(\eta-\varepsilon) f_{h}(\varepsilon) d \varepsilon, \quad(\mathrm{A}
\end{gathered}
$$

where $F_{h}(\varepsilon)$ is the cumulative distribution function of $\varepsilon_{t}^{h}$ and $f_{h}(\varepsilon)$ its probability density function. An increase in $q$ induces an increase in $\hat{\eta}_{t}^{h}$ in the sense of first-order stochastic dominance because:

$$
\int_{-\infty}^{\infty} \varepsilon F_{h}(\eta-\varepsilon) f_{h}(\varepsilon) d \varepsilon=\mathbb{E}\left[\varepsilon_{t}^{h} F_{h}\left(\eta-\varepsilon_{t}^{h}\right)\right]<\mathbb{E} \varepsilon_{t}^{h} \mathbb{E}\left[F_{h}\left(\eta-\varepsilon_{t}^{h}\right)\right]=0 .
$$

The growth rate of output is:

$$
\log y_{t+1}-\log y_{t}=\log A+(1-\alpha) \log [\beta(1-\alpha)-\zeta]+\alpha \log (\beta \alpha)+(1-\alpha) \hat{\eta}_{t}^{h} .
$$

The equilibrium distribution of $\hat{\eta}_{t}^{h}$ has raw moments:

$$
\mathbb{E} \hat{\eta}_{t}^{h}=\mathbb{E}\left(\chi_{t-1} \varepsilon_{t-1}^{h}\right)=\frac{(1-\alpha) \beta}{1-\beta} \theta(p, q) \phi \sigma_{h}^{2}
$$

and

$$
\begin{aligned}
\mathbb{E}\left[\left(\hat{\eta}_{t}^{h}\right)^{2}\right]= & \mathbb{E}\left[\chi_{t-1}\left(\varepsilon_{t-1}^{h}+\varepsilon_{t}^{h}\right)^{2}\right]+\mathbb{E}\left(1-\chi_{t-1}\right) \mathbb{E}\left[\left(\omega_{t-1}^{h}+\omega_{t}^{h}\right)^{2}\right] \\
= & \mathbb{E}\left[\chi_{t-1}\left(\varepsilon_{t-1}^{h}\right)^{2}\right]+\mathbb{E} \chi_{t-1} \mathbb{E}\left[\left(\varepsilon_{t}^{h}\right)^{2}\right] \\
& +\mathbb{E}\left(1-\chi_{t-1}\right)\left\{\mathbb{E}\left[\left(\omega_{t-1}^{h}\right)^{2}\right]+\mathbb{E}\left[\left(\omega_{t}^{h}\right)^{2}\right]\right\} \\
= & \mathbb{E}\left[\chi_{t-1}\left(\varepsilon_{t-1}^{h}\right)^{2}\right]+\frac{3}{2} \sigma_{h}^{2} \\
= & \frac{(1-\alpha) \beta}{1-\beta} \theta(p, q) \phi \mathbb{E}\left[\left(\varepsilon_{t-1}^{h}\right)^{3}\right]+2 \sigma_{h}^{2},
\end{aligned}
$$


so the variance of the output growth rate is:

$$
\begin{aligned}
& \operatorname{Var}\left(\log y_{t+1}-\log y_{t}\right)=(1-\alpha)^{2} \operatorname{Var}\left(\hat{\eta}_{t}^{h}\right) \\
& =(1-\alpha)^{2}\left\{\frac{(1-\alpha) \beta}{1-\beta} \theta(p, q) \phi \mathbb{E}\left[\left(\varepsilon_{t-1}^{h}\right)^{3}\right]+2 \sigma_{h}^{2}-\left[\frac{(1-\alpha) \beta}{1-\beta} \theta(p, q) \phi \sigma_{h}^{2}\right]^{2}\right\} \\
& =(1-\alpha)^{2}\left\{2 \sigma_{h}^{2}-\left[\frac{(1-\alpha) \beta}{1-\beta} \theta(p, q) \phi \sigma_{h}^{2}\right]^{2}\right\}
\end{aligned}
$$

given that $\mathbb{E}\left[\left(\varepsilon_{t-1}^{h}\right)^{3}\right]=0$ since the distribution of $\varepsilon_{t-1}^{h}$ is symmetric around $\mathbb{E} \varepsilon_{t-1}^{h}=0$. 